\title{
Antimicrobial properties of viscose yarns ring-spun with integrated amino-functionalized nanocellulose
}

\author{
Vanja Kokol (D) Vera Vivod · Zdenka Peršin • Miodrag Čolić • \\ Matjaž Kolar
}

Received: 5 August 2020/Accepted: 13 May 2021/Published online: 27 May 2021

(C) The Author(s) 2021

\begin{abstract}
Bio-based, renewable and biodegradable products with multifunctional properties are also becoming basic trends in the textile sector. In this frame, cellulose nanofibrils (CNFs) have been surface modified with hexamethylenediamine/HMDA and used as an antimicrobial additive to a ring-spun viscose yarn. The CNF-HMDA suspension was first characterized in relation to its skin irritation potential, antimicrobial properties, and technical performance (dispersability and suspensability in different media) to optimize its sprayability on a viscose fiber sliver with the lowest sticking, thus to enable its spinning without flowing and tearing problems. The impact of CNF-HMDA content has been examined on the yarn's fineness, tensile strength, surface chemistry, wettability and antimicrobial properties. The yarn's antimicrobial properties were increasing with the
\end{abstract}

V. Kokol $(\bowtie) \cdot$ V. Vivod $\cdot$ Z. Peršin

Faculty of Mechanical Engineering, University of

Maribor, Maribor, Slovenia

e-mail:vanja.kokol@um.si

M. Čolić

Institute for the Application of Nuclear Energy (INEP),

University of Belgrade, Belgrade, Serbia

M. Čolić

Medical Faculty Foča, R. Srpska, University of East

Sarajevo, Sarajevo, Bosnia and Herzegovina

M. Kolar

Litia Spinnery, LtD, Litija, Slovenia content of CNF-HMDA, given a 99\% reduction for $S$. aureus and $C$. albicans ( $\log 1.6-2.1)$ in up to $3 \mathrm{~h}$ of exposure at minimum $33 \mathrm{mg} / \mathrm{g}$, and for E. coli (log $0.69-2.95)$ at $100 \mathrm{mg} / \mathrm{g}$ of its addition, yielding $45-21 \%$ of bactericidal efficacy. Such an effect is related to homogeneously distributed CNF-HMDA when sprayed from a fast-evaporated bi-polar medium and using small $(0.4 \mathrm{~mm})$ nozzle opennings, thus giving a high positive charge $(0.663 \mathrm{mmol} / \mathrm{g})$ without affecting the yarn's tenacity and fineness, but improving its wettability. However, a non-ionic surfactant being used in the durability testing of functionalized yarn to 10-washing cycles, adheres onto it hydrophobically via the methylene chain of the HMDA, thus blocking its amino groups, and, as such, decreasing its antibacterial efficiency, which was slightly affected in the case when the washing was carried out without using it.

Keywords Cellulose nanofibrils · Amination - Skin irritation · Viscose fibers · Ring-spinning ·

Antimicrobial properties

\section{Introduction}

An awareness of general sanitation, contact disease transmission and personal protection, has led to the development of antimicrobial finished fibers for controlling infection by microbes, thereby protecting 
the wearers (Gokarnshan et al. 2017), as well as the textile itself against the spread of bacteria and diseases. Effective antimicrobially active fibres are generally obtained by chemical or physical attachment of bacteriostatic and biocidal agents such as aminecontaining compounds, which rely on electrostatic interactions with anionic bacteria (Lim and Hudson 2003; Liu and Sun 2006; Ren et al. 2016; Dumont et al. 2018) or quaternary ammonium salts with four alkyl or aryl points of attachment to the nitrogen, yielding a permanent positive charge $\left(\mathrm{NR}_{4}{ }^{+}\right)$(Kang et al. 2016; Kim and Sun 2001), alone, or in combination with metals or metal oxides (as e.g. $\mathrm{ZnO}, \mathrm{SiO} 2, \mathrm{MgO}$, $\mathrm{TiO} 2, \mathrm{Ag}+$ ) in the form of nanoparticles (Velmurugan et al. 2014; Varaprasad et al. 2016; Milošević et al. 2017; Prado-Prone et al. 2018; El-Naggar et al. 2018; Kwak et al. 2019; Zhou et al. 2018), thus acting against a broad spectrum of Gram-positive $(\mathrm{G}+)$ and Gramnegative (G-) bacteria, fungi and even some viruses, due to the diverse mechanisms of actions (Borkow et al. 2010; Rezaie et al. 2017; Marković et al. 2018; Ibrahim et al. 2019; Hasan 2018).

Due to general eco- (Adams et al. 2006) and biotoxic concern related to the usage of nanoparticles, causing side effects or antimicrobial resistance, as well as the reusing ability of textiles being finished with non-biodegradable/compostable polymers, the use of natural agents, such as plant-derived extracts (Upadhyay et al. 2014; Ganesan et al., 2015; Vastrad and Byadgi 2018; El-Shafei et al. 2018) and animalderived chitosan (Lim and Hudson 2003; Dumont et al. 2018), has become atrractive non-allergic and non-toxic textile finishing, also bringing an absorbency and moisture control.

Conventionally, such antimicrobial agents are applied to the textile substrates by exhausting (Ali Elshafei \& El-Zanfaly 2011; Ganesan and Vardhini 2015), padding (Xu et al. 2018; Rajendra et al. 2010), spraying (Sataev et al. 2014; Jahani et al. 2018) or foam coating (Song et al. 2013; Nayak \& Padhye 2015), providing a uniform film on the surface as a mono or multi-layer assembly process (Hui \& Debiemme-Chouvy 2013; Ugur et al. 2016; Chen et al. 2016), being attached by a physical or chemical approach using, e.g., click (Sun et al. 2019), polymerization-graft (Hui and Debiemme-Chouvy 2013; He et al. 2016) and sol-gel (Camlibel and Arik 2017; Poli et al. 2015; Mahltig and Textor 2010; Liu et al. 2012) chemistry approach, or UV irradiation (Ferrero et al.
2015; Periolatto et al. 2012), thus resulting in a sustainable and durable antimicrobial finish. On the other hand, in the case of synthetic or man-made fibers, the antimicrobial agents are incorporated into the polymer solution physically, which is spun into the filaments or fibers by extrusion. In that frame, electrospinning has also become an attractive process enabling production of antimicrobial nanofiber nets by using versatile polymers and additives, to be applied in biomedicine (Agarwal et al. 2012; Rieger and Schiffman 2014; Sridhar et al. 2015; Pajoumshariati et al. 2016), wound dressings (Suganya et al. 2011; Khan et al. 2019) and protective textiles (Kampeerapappun 2012; Gorji et al. 2017; Teli et al. 2017).

However, most commercially available antimicrobially active polymers or (nano)materials lack biodegradability or recyclability, and thus have limited applications where recyclability and renewability are of interest. Besides, although conventional manmade or natural fibers satisfy the bio-degradability requirements, they cannot compete with synthetic fibers in terms of performance. Moreover, there is an increasing interest in selective application of antimicrobial agents with potency against bacteria and nontoxicity towards mammalian cells, among which the polymeric-based antimicrobial agents have the advantage, as they are nonvolatile, chemically stable, and find it difficult to permeate through the skin, as well as minimize the environmental problems.

Cellulose nanofibrils (CNFs), derived mechanically from wood pulp, are widely regarded as added-value materials by offering interesting physical and mechanical properties, making them potential candidates for a wide variety of applications to solve the abovementioned issues of current materials (Dufresne 2013; Abitbol et al. 2016). CNF-based filaments, produced by dry- or wet-spinning processes (Hooshmand et al. 2015; Ghasemi et al. 2017), have been introduced recently as potential high-tech textile products. However, there are still no reports available to provide information on the effects of using CNFs as a functional additive into a conventional production of fiber yarns using a ring-spinning process, while its incorporation into biopolymers by extrusion was established recently (Alam and Christopher 2017).

The aim of this research was, thus, to integrate hexamethylenediamine (HMDA) functionalized CNFs (CNF-HMDA; Jin et al. 2015; Vivod et al. 2019) into viscose yarn, produced by a conventional 
ring-spinning process, to obtain a yarn with antimicrobial properties, being related to the HMDA surface attached to the CNFs. Diamines as HMDA have been used as functional monomers to design amine-terminated nanocellulose (Hemraz et al. 2013) or polymers (Gün Gök et al. 2020) with antimicrobial properties to be applied in the preparation of hygenic paper products (Xiao and Qian 2014), biopolymers for biomedicine (Hemraz et al. 2013; Gün Gök et al. 2020; Alamri et al. 2012), and products for biological water tretment (Alamri et al. 2012). However, because HMDA may have minimal impact on overall toxicity (Harper et al. 2016), although its leaching from CNFHMDA is unlikely due to its covalent linkage, we performed skin irritation testing of CNF-HMDA on rabbits to verify its potentially harmful effect on skin contact.

In order to enable smooth spinning of a sliver during twisting without its tearing, evenly distributed application of highly hydrophilic and gel-like CNFHMDA suspension on a viscose sliver without physical adhesion of the fibers (or even their gluing) during drying was essential. The spraying technique and a fast-drying media were used for that purpose. The CNF-HMDA suspension dispersability into different fast-volatile media and sprayability were thus first examined using different concentrations and sizes of nozzles. The optimized spraying processes were then used to prepare fiber slivers with CNF-HMDA of various amounts, and check their spinning ability into a continuous functional yarn. The yarn functionalities have been evaluated as tenacity, fineness, surface charge, wettability and antimicrobial properties.

\section{Experimental}

\section{Materials}

The chain-like cellulose nanofibrils (CNFs), with diameters in the 10-70 $\mathrm{nm}$ range and length of the micrometer scale, were supplied from the University of Maine, The Process Development Center in the USA. The $100 \%$ viscose fibers, of 1.3 dtex and $39 \mathrm{~mm}$ long produced by Lenzing AG, were prepared as a compact sliver (of $1.2 \mathrm{ktex}$ and $21.5 \mathrm{Nm}$ ) by Litija Spinnery Ltd according to the conventional industrial process (including mixing, carding, drawing, and roving steps) and used throughout the study.
Hexamethylenediamine (HMDA, 98\% purity) and all other chemicals used were purchased from SigmaAldrich Co. Ltd. (USA), and used without further purification.

Functionalization of CNFs with HMDA

The functionalization of CNFs with HMDA was performed by the following two-step procedure presented in Fig. 2 (Vivod et al. 2019; Jin et al. 2015): Sodium periodate oxidation of CNFs to dialdehyde (CNF-ald) and further reaction with HMDA through a Schiff-based reaction to obtain CNF-ald-HMDA (marked as CNF-HMDA through the paper). Briefly, $100 \mathrm{~mL}$ of CNFs $(1 \mathrm{wt} \%$ ) and $1.9 \mathrm{mmol} / \mathrm{g}$ amount of sodium periodate were mixed, and stirred for $48 \mathrm{~h}$ in the absence of light at room temperature. The residual sodium periodate was then removed by adding $10 \mathrm{~mL}$ of ethylene glycol. The product was dialyzed against deionized water for 3 days using a dialysis membrane with a molecular weight cut-off of 12.000-14.000. $200 \mathrm{~mL}$ of CNF-ald suspension $(0.5 \mathrm{wt} \%)$ was ultrasonicated for $5 \mathrm{~min}$, and then $8 \mathrm{mmol}$ of HMDA was added. The mixture was stirred continuously for $6 \mathrm{~h}$ at $30{ }^{\circ} \mathrm{C}$, followed by the in-situ reduction of the resulting imine intermediate at room temperature, employing $0.58 \mathrm{~g}$ of $\mathrm{NaBH}_{4}$. After stirring for $3 \mathrm{~h}$, the product CNF-HMDA was dialyzed (MWCO: 12.000-14.000) against deionized water until it reached a neutral $\mathrm{pH}$, and used as prepared.

\section{Skin irritation test of CNF-HMDA}

A skin irritation test was performed on Albino rabbits (4 animals) according to the ISO 10,993-10:2012 (Biological evaluation of medical devices-Part 10: Tests for irritation and skin sensitization) in the Laboratory for the biocompatibility study, Institute for the Application of Nuclear Energy (INEP), Belgrade, Serbia. The study was approved by the Ethical Committee of INEP for Protection and Welfare of Experimental Animals (No: 02-763/4) and additionally decided by the Ministry of Agriculture, Forestry and Water Economy of the Republic of Serbia-Veterinary Directorate (No: 323-07-11,160). The study fully complies with the ISO 10,993-2 Animal welfare requirements. Three animals were used for test samples and negative control, whereas one rabbit was used as a positive control. Briefly, 
suspensions of $3 \mathrm{wt} \%$ CNF-HMD (total 6 test samples) were applied on fur-clipped skin (the back dorsolateral surface) of rabbits (two samples per rabbit). The application area was about $8 \mathrm{~mm}$ in diameter. Two application areas on each rabbit served as the places for the negative control (application of physiological saline). Four different application areas on one rabbit served as the positive control (application of concentrated $\mathrm{HCl}$ ), following the same procedure. The CNF-HMD suspension and control samples were left in contact with the skin for a period of $2 \mathrm{~h}$, after which the application procedure was repeated on the same places and the samples were left for an additional $2 \mathrm{~h}$. After that, the CNF-HMD samples were removed carefully and washed with physiological saline. All application sites were marked with a permanent marker.

The observation of skin lesions was done for 1, 24, 48 and $72 \mathrm{~h}$ after the removal of the test preparations. Skin changes were evaluated for each application site and each time interval. The Irritation Score (IS) and Primary Irritation Index (PII) were determined as suggested by ISO 10,993-10:2012: IS $=($ oedema + erythema $) /$ number of readings, and PII = Irritation Score/ number of application sites. According to the values of PII, the test samples were classified as non-irritating (0.0-0.4), slightly irritating (0.5-1.9), irritating (2.0-4.9), and strongly irritating (5.0-8.0).

Spraying of CNF-HMDA suspensions

An Airbrush Colani gun (Harder \& Steenbeck) with nozzle-exchange capability of different nozzle sizes $(0.4-1.2 \mathrm{~mm})$ and air pressure of $\sim 3$ bars was used to study the sprayability of different CNF-HMDA suspensions and their application on the viscose fiber sliver.

Ring-spinning of viscose sliver

Ring-spinning was performed on a laboratory ringspinning machine RM350 / D45 (Mesdan Spa, Italy) according to the following procedure: $630 \mathrm{rpm}$ of twisting $10.000 \mathrm{rpm}$ of spindles, and $15.9 \mathrm{~m} / \mathrm{min}$ of drain speed. The following technological settings were used: $65 \mathrm{~mm}$ length of pre-expansion field, $45 \mathrm{~mm}$ length of main expansion field, and using a $5.15 \mathrm{~mm}$ beige spacer on a cradle and travelers C2RF No. 4 (Reiners + Fürst GmbH, Germany).

Zeta-potential and particle-size distribution (PSD) analysis of CNF-HMDA suspensions

The Zeta-Potential and PSD values of native and HMDA-modified CNF suspensions in different media (milliQ water, ethanol, aceton) were carried out on a Zetasizer (Nano ZS ZEN360, Malvern Instruments Ltd., UK) at $25 \pm 0.1{ }^{\circ} \mathrm{C}$, using the DTS1070 disposable folded capillary cell, applying the following parameters: A material refractive index of 1.47 (cellulose), dispersion refractive index of 1.33 (milliQ), 1.363 (EtOH) and 1.357 (aceton), and viscosity of $0.8872 \mathrm{cP}$ (milliQ), $1.1734 \mathrm{cP} \quad(\mathrm{EtOH})$ and $0.3084 \mathrm{cP}$ (aceton). A field of $150 \mathrm{~V}$ was applied across the nominal electrode spacing of $16 \mathrm{~mm}$. The samples were prepared at concentrations of $0.01 \mathrm{w} /$ $\mathrm{v} \%$ in Milli-Q water and measured over a $\mathrm{pH}$ range from 3 to 11, being adjusted using $0.1 \mathrm{M} \mathrm{NaOH}$ and $0.1 \mathrm{M} \mathrm{HCl}$, respectively. Ultrasound was applied to get well dispersed particles before being fed to the measuring zone, and the scattered laser light intensity was quantified in order to calculate the PSD resulting from the particle scattering pattern. The average values were calculated from at least four individual measurements.

Attenuated total reflectance-fourier transform infrared (ATR-FTIR) analysis

The IR spectra of CNF-HMDA, as well as corresponding CNF-HMDA functionalized yarns, before and after the washings, were recorded using a PerkinElmer spectrum one FTIR spectrometer with a Golden Gate ATR attachment and a diamond crystal. The spectra were carried out at ambient conditions from accumulating 16 scans at a $4 \mathrm{~cm}^{-1}$ resolution over a region of $4000-650 \mathrm{~cm}^{-1}$, and with air spectrum subtraction performed in parallel as a background. The Spectrum 5.0.2 software program was applied for the data analysis. All the measurements were carried out in duplicate.

\section{Potentiometric titration analysis}

Potentiometric titration of CNF water dispersions, as well as yarns functionalized with CNF-HMDA was 
performed for quantifying the processing-dependant surface charge contribution. The titration was carried out using a dual-burette instrument (Mettler Toledo T-70), equipped with a combined glass electrode (Mettler TDG 117). The burettes were filled with $0.1 \mathrm{M} \mathrm{HCl}$ (Merck, Titrisol) and 0.1 M KOH (Baker, Dilut-it). Samples were rinsed in low pH $(0.01 \mathrm{M} \mathrm{HCl})$ to convert basic and acidic groups into protonated forms, soaked in Milli-Q water and, afterwards, dried at $40{ }^{\circ} \mathrm{C}$ ). Titration was carried out at room temperature $\left(23 \pm 1^{\circ} \mathrm{C}\right)$ in forward and back runs between $\mathrm{pH} 2$ and 11. From the potentiometric titration data, the molar concentration relating to the overall charge of the weak ions was calculated (arising from the side groups of CNF and HMDA). All the reported values are the mean values of duplicate determinations.

Wetting properties of the yarns

The wetting properties of yarn samples were determined according to the capillary rise method, using the Tensiometer K12 (Krüss, GmbH Germany) and a special sample holder filled with $1 \mathrm{~g}$ of densely packed sample. The glass vessel, filled with $75 \mathrm{~mL}$ of milliQ water as the wetting liquid, was placed into the moving table, which rose until the tested liquid touched the lower edge of the sample holder. The software (Kruss, version 2.5.0.2305, LabDesk User Interface) monitored the increase in mass of the sample cylinder with respect to the capillary action and the time during the measurement. Since the sample was densely packed as a bundle of capillaries, the modified Washburn equation was used to present the linear dependency of the square height penetration of the testing liquid in the cylinder $v s$. time, according to the following equations:

$\frac{m^{2}}{t}=\frac{c \cdot \rho^{2} \cdot \gamma \cdot \cos \varphi}{\eta}$

$\left.c=\frac{1}{2} \cdot \pi^{2} \cdot \overline{(r}^{5}\right) \cdot n^{2}$

where $n$ presents the number of micro capillaries and their mean radius $(\bar{r})(\mathrm{mm})$ in bulk material, $m(\mathrm{~g})$ is the mass of absorbed test liquid, $\varphi\left({ }^{0}\right)$ is the Contact Angle (CA) between the tested liquid and solid sample, while $\rho\left(\mathrm{g} \mathrm{cm}^{-3}\right)$ is the density, $\gamma\left(\mathrm{Nm}^{-1}\right)$ is the surface tension, and $\eta(\mathrm{Pa})$ is the viscosity of the tested liquid. The constant $c$ includes the number of microcapillaries and their mean radius of the cylinder, and depends on the measured sample and physical properties of the tested liquid. To determine the constant $c$, a measurement was carried out with an optimally wetting (spreading) liquid (in our case n-hepane), with a CA $(\varphi)$ of $0^{\circ}(\cos \varphi=1)$. The obtained $c$ value was used for measuring the weight increase $v s$. time $\left(\mathrm{mass}^{2} / t\right)$ using milliQ water, as well as to calculate the CA. The obtained slopes of weight gained due to the milliQ water penetration as a function of time, presents the sample's absorbency rate, while the amount of test liquid uptake (g milliQ/ g) in equilibrium expressed their absorbent capacities. The measurements with both liquids were performed at least 5 times for each sample, in order to obtain statistically significant results.

Scanning electron microscopy (SEM) imaging

The structure of native and HMDA-modified CNFs, as well as their dispersability in different media and corresponding ring-spun viscose yarns, were characterized by using a low-vacuum microscope (FEI Quanta 200 3D).

\section{Determination of antimicrobial activity}

The Minimal Inhibitory Concentration (MIC) of CNFHMDA suspensions and antibacterial efficacies of CNF-HMDA integrated viscose yarns were provided by the National Laboratory of Health, Environment and Food (NLZOH), Maribor, Slovenia, according to the standard test method E2149-10 using Gramnegative (G-) bacterium Escherichia coli (E. coli, DSM 1576), Gram-positive ( $\mathrm{G}+$ ) bacterium Staphylococcus aureus (S. aureus, DSM 799), and skin fungus Candida Albicans (DSM 1386) as testing microorganisms.

The CNF-HMDA suspensions (differently concentrated) or CNF-HMDA functionalized viscose yarns ( $1 \mathrm{~g})$ were added, or soaked in a testing buffer (0.3 mM potassium phosphate buffer of $\mathrm{pH}$ 7.2) for one hour, respectively. Bacterial cell suspensions with a final concentration of $1 \times 10^{8} / 1.5 \times 10^{7}$ ColonyForming Units (CFU)/mL and fungal cell of $1.5 \times 10^{5} \mathrm{CFU} / \mathrm{mL}$, both in $0.3 \mathrm{mM}$ potassium phosphate buffer of $\mathrm{pH}$ of 7.2, were prepared and added to the CNF-HMDA suspension or viscose yarn to a final volume of $50 \mathrm{~mL}$. Control experiments were run, 
during which no samples were present within the microorganism culture, and treated in the same way. After the contact period ( $1 \mathrm{~h}$ for suspensions, $1-6 \mathrm{~h}$ for yarns), the samples were submitted to serial dilutions and plated in triplicates. In the case of suspensions, microorganism growth (tube opacity) was read; the last dilution in which microbial growth was no longer detectable is the MIC value. In the case of yarn samples, the CFUs were counted after an overnight incubation at $37 \pm{ }^{\circ} \mathrm{C}$, and the mean values of percent reduction $(\mathrm{R}, \%)$ were calculated using the following equation: $\mathrm{R}=\left(\mathrm{N}_{0}-\mathrm{N}\right) / \mathrm{N}_{0} \times 100$, where $\mathrm{N}_{0}$ and $\mathrm{N}$ are the numbers of bacteria/fungal colonies on the samples before and after the test, respectively. The reduction factor $(\log (\mathrm{N} 0 / \mathrm{N})$ was also given.

In addition, the agar diffusion test (ISO 20,645) was performed to evaluate the inhibition zone. The yarn samples (rolled in to small balls) were soaked in a testing buffer for one hour, and then laid on nutrient agar plates inoculated with the test bacteria of $1.2 \times 10^{6} \mathrm{CFU} / \mathrm{mL}$ in the same buffer media as stated above. The paper disks (6 mm in diameter) with $15 \mathrm{uL}$ of $3.2 \mathrm{wt} \%$ CNF-HMDA suspension were used in the same way. After incubation for $24 \mathrm{~h}$ at $37 \pm 0.5^{\circ} \mathrm{C}$, the plates were examined for bacterial growth directly underneath the sample and above, as well as around its edges, by measuring the diameter of the zone of inhibition in different directions (because the samplers were not perfectly round) and in comparison to the control samples. The experiment was performed in duplicate and the mean value was taken.

Bacterial viability and bactericidal assessment using the Live-Dead test

The working suspensions were prepared of the selected bacteria, E. coli $\left(2 \times 10^{8}\right.$ bacteria/mL $)$ and S. aureus $\left(2 \times 10^{7}\right.$ bacteria $\left./ \mathrm{mL}\right)$. After $24 \mathrm{~h}$ of inoculating yarn substrates with bacteria cells using working bacterial suspensions (as described above), a stock solution $(1.5 \mathrm{~mL})$ of Live/Dead BacLight staining reagent mixture $(6 \mu \mathrm{M}$ SYTO 9 and $30 \mu \mathrm{M}$ PI) was mixed with $1.5 \mathrm{~mL}$ of each bacterial suspension, which remained after shake flask testing. The solutions were incubated at room temperature in the dark for $15 \mathrm{~min}$ and then each pipetted $(100 \mu \mathrm{L})$ into separate wells of 96-well flat-bottomed micro-plates, and measured using the fluorescence mission spectrum using a Tecan Spectrophotometer. The viable bacteria (live cells) were stained with SYTO 9 to a green fluorescent color, whereas the bacteria with damaged membranes (dead cells) were stained with PI to a red fluorescent color. By using an excitation wavelength centered at $480 \mathrm{~nm}$, the integrated intensities of the green $(G ; 530 \mathrm{~nm})$ and red $(R ; 630 \mathrm{~nm})$ emission were acquired, and the green/red fluorescence ratios (Ratio $G / R)$ were calculated for each suspension. The biocidal effects (\%) against both bacteria were determined by calculating the relationship between Live $(G$, $x)$ bacteria and $G / R$ fluorescence ratio $(y)$ as $\left[y_{1}=0.067 x+0.6635\right]$ for $E$. coli and $\left[y_{2}=0.0177 x+2.1017\right]$ for $S$. aureus. Experiments were performed in duplicate, and the data are shown as the mean value, containing the Standard Deviation.

The biocidal efficiencies of the samples were examined further by viability tests, performed by using confocal microscopy and fluorescence spectroscopy. After $24 \mathrm{~h}$ of exposure to the media inoculated with E. coli $\left(10^{5} \mathrm{CFU} / \mathrm{mL}\right)$ or $S$. aureus $\left(10^{5} \mathrm{CFU} / \mathrm{mL}\right)$, the yarn samples were stained with $3.4 \mu \mathrm{M}$ of SYTO 9 and $6.0 \mu \mathrm{M}$ of PI, respectively, for $30 \mathrm{~min}$ in the dark at room temperature, washed with Milli-Q water, air-dried, and then visualized by an inverted confocal laser scanning microscope Axio Observer Z1 LSM 710 (ZEISS, Germany) with an EC "Plan-Neofluar" 20x/0.50 M27 objective. Fluorophores were excited using an argon laser (488 nm) and the emitted light was collected through SP 545 and LP 605 filters.

Determination of fineness and mechanical properties of the yarns

The manufactured yarns were determined by mechanical properties on the automatic Statimat CU (Textechno H. Stein GmbH \& Co. KG, Germany) machine at $25 \pm 1{ }^{\circ} \mathrm{C}$ and $45 \pm 1 \%$ humidity, monitored with the Texcount software. The results are presented as representative data or mean $\pm \mathrm{SD}$ values of up to 10 independent measurements.

Washing resistance of the yarns

The washing procedure, which consisted of 10 consecutive cycles, was carried out according to the Standard ISO 105-C01:1989 with and without the addition of $5 \mathrm{~g} / \mathrm{L}$ washing agent, using the LABOMAT device (W. Mathis AG, Oberhasli, Switzerland). 
The yarn samples were placed into LABOMAT beakers and the necessary amount of pre-heated $\left(\sim 40{ }^{\circ} \mathrm{C}\right)$ milliQ water was added to give a liquid:sample ratio of 50:1. The samples in beakers were placed into the machine and washed at $40 \mathrm{rpm}$ for $30 \mathrm{~min}$ at $40 \pm 2{ }^{\circ} \mathrm{C}$. After each cycle the samples were taken out of the beaker, squeezed, put back in the beaker, and covered with fresh milliQ water. After 10 washing cycles, the samples were opened-out manually, laid on the filter paper and dried out at room temperature.

\section{Results and discussion}

\section{Skin irritation potential of CNF-HMDA}

The testing of $3 \mathrm{wt} \%$ CNF-HMD suspension, performed on Albino rabbits (Fig. 1) according to the ISO 10,993-10:2012, can be classified as skin non-irritating $(\mathrm{PII}=0.0)$, identically as the negative control (physiological saline), while positive control (concentrated $\mathrm{HCl}$ ) has been classified as irritating $(\mathrm{PII}=3.2)$.

CNF-HMDA dispersibility in different media and sprayability

The spraying process was first optimized in terms of CNF-HMDA dispersibility using different CNFHMDA concentrations, suspension mediums and sizes of nozzle openings. The effect of CNF-HMDA dispersibility in fast-volatile mediums was thus analyzed by Zeta-Potential (ZP) and size-distribution values, as well as by SEM imaging of samples sprayed on Aluminum foil.
In order to identify the charge contribution from CNF and HMDA on dispersibility, the CNF suspension was also analyzed by potentiometric titration after different modification steps (Fig. 2), i.e. the oxidation (1st step) with sodium periodate $\left(\mathrm{NaIO}_{4}\right)$, forming a pair of aldehyde groups (CNF-ald) by cleaving the $\mathrm{C} 2-\mathrm{C} 3$ bond of anhydro-glucopyranoside ring, and the binding of HMDA (2nd step) through a Schiff-base reaction, yielding CNF-ald-HMDA. The titration curve of native $\mathrm{CNF}$ shows one small bend at $\mathrm{pH}$ 4.4 , given the small quantity $(0.12 \mathrm{mmol} / \mathrm{g})$ of negative charge that may be related to the presence of rare anionic (preferably sulphonate and carboxylic) surface groups, formed during the preparation of CNF or resulting from the presence of lignin residues. These groups were reduced to $0.096 \mathrm{mmol} / \mathrm{g}$ after the oxidation (CNF-ald), also giving another peak at $\mathrm{pH} \sim 9.1$, which might be related to the aforementioned phenomenon, while they could not be detected anymore after attachment of HMDA (CNF-aldHMDA), yielding a positive charge of around $5.64 \mathrm{mmol} / \mathrm{g}$ at $\mathrm{pH} \sim 8.1$. The titration curve of pure HMDA (inserted chart) shows high positive charge at a wide $\mathrm{pH}$ range until $\sim 10.7$ (being related to its complete deprotonation, $\mathrm{pK}$ ) with a small band between $\mathrm{pH}$ 6.0-7.0 (representing the partial deprotonation stage of diamines, $\left.\mathrm{H}_{2} \mathrm{~N}-\left(\mathrm{CH}_{2}\right)_{6}-\mathrm{NH}_{2}\right)$, thus confirming the high contribution of amino $\left(\mathrm{CNF}-\mathrm{NH}_{2}\right)$ groups. A gradual reduction of the titration curve for the CNF-ald-HMDA sample and shifting of HMDA's $\mathrm{pK}$ value towards lower $\mathrm{pH}$ may, thus, be because of its binding to CNF-ald. In order to identify the efficacy of the HMDA attachement on aldehydes, the sequential/second-step oxidation of CNF-ald was also performed with sodium chlorite (NaIO4) (CNF-ald$\mathrm{COOH}$; Liimatainen et al. 2012) which, however,
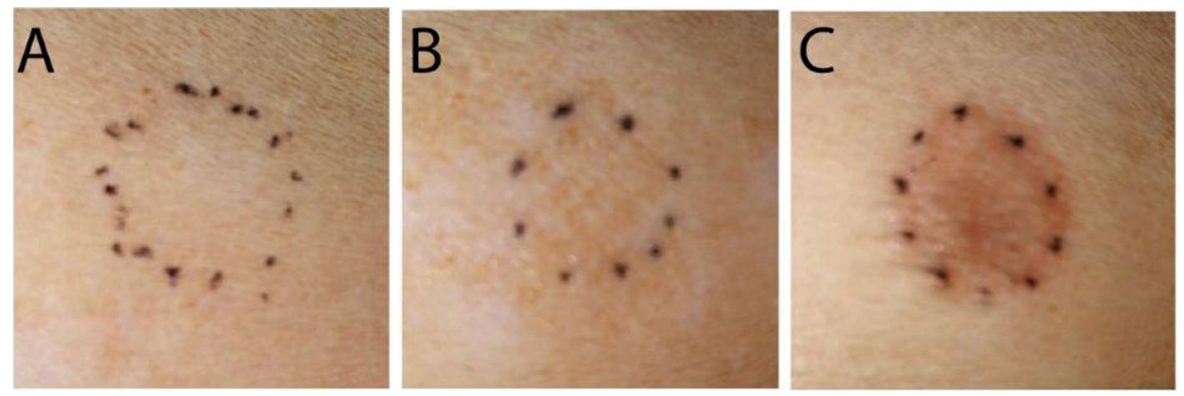

Fig. 1 Selected photos of skin irritation reaction on rabbit skin, taken one hour after removal of the samples: a Non-irritating (3 wt $\%$ ) CNF- HMD, b Non-irritating negative control (physiological saline), and c Irritating positive control (concentrated HCl) 

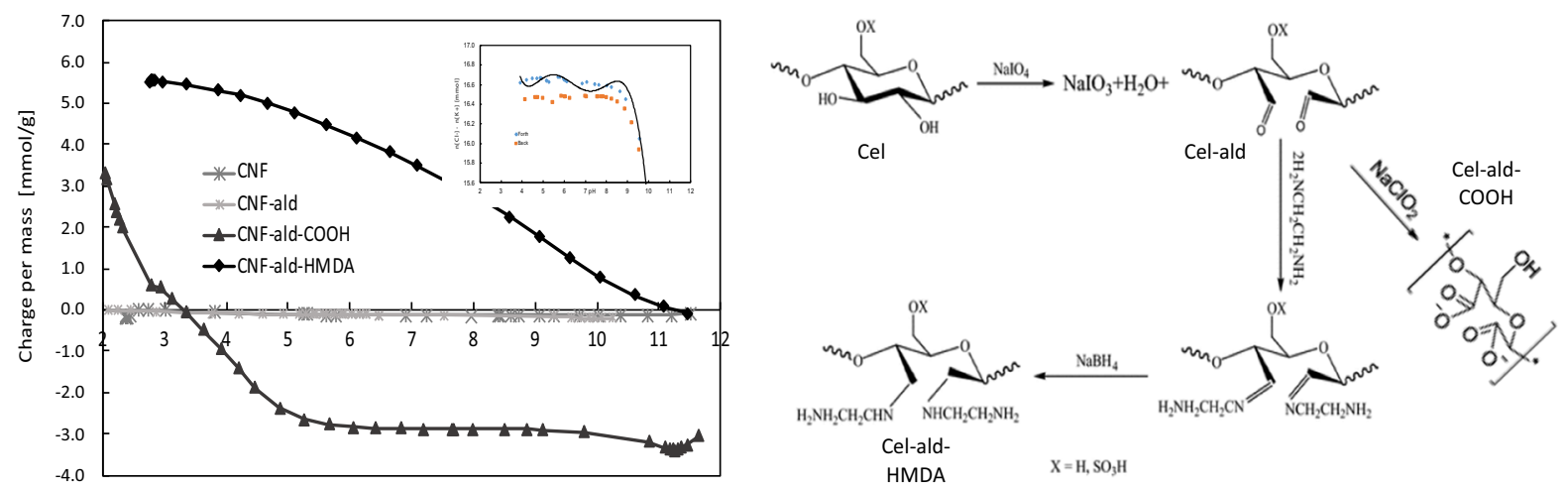

$\mathrm{pH}$
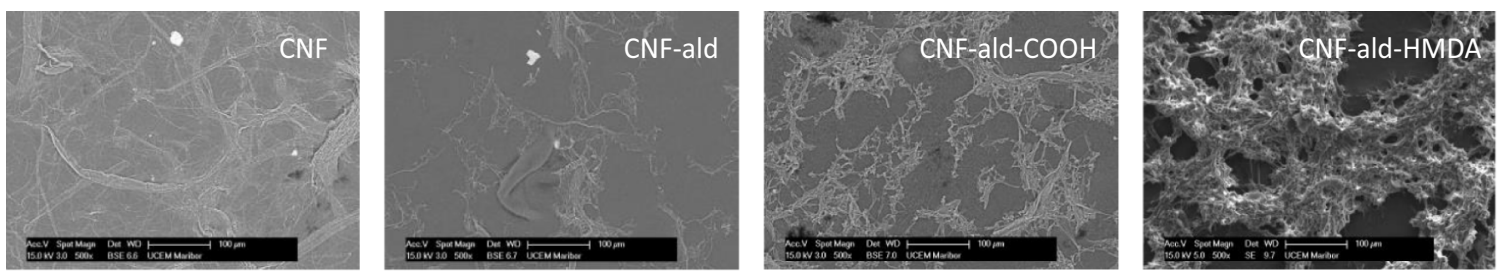

\begin{tabular}{|l|c|c|c|c|c|}
\hline Sample & pK1 & $\begin{array}{c}\text { Charge pK1 } \\
(\mathrm{mmol} / \mathrm{g})\end{array}$ & $\mathrm{pK} 2$ & $\begin{array}{c}\text { Charge pK2 } \\
(\mathrm{mmo1} / \mathrm{g})\end{array}$ & $\begin{array}{c}\text { Charge } \\
\text { TOTAL } \\
(\mathrm{mmol} / \mathrm{g})\end{array}$ \\
\hline HMDA & $/$ & $/$ & 10.7 & n.d. & n.d. \\
\hline CNF-REF & 4.4 & 0.121 & $/$ & $/$ & 0.121 \\
\hline CNF-ald & 3.2 & 0.096 & 9.1 & 0.094 & 0.189 \\
\hline CNF-ald-COOH & 4.1 & 3.444 & $/$ & $/$ & 3.444 \\
\hline CNF-ald-HMDA & $/$ & $/$ & 8.1 & 5.640 & 5.640 \\
\hline
\end{tabular}

Fig. 2 Potentiometric titration curves with corresponding charges (inserted Table) of HMDA and different $(0.5 \mathrm{wt} \%)$ CNF-based water-dispersions, prepared according to different

gave a much smaller amount of carboxylic acid groups $(\sim 3.44 \mathrm{mmol} / \mathrm{g})$ as would be expected stoichiometrically. This might be due to the incomplete oxidation of aldehydes, because the aldehyde content on CNFald determined by hydroxylamine hydrochloride $\left(\mathrm{HONH}_{2} \cdot \mathrm{HCl}\right)$ according to (Kim et al. 2004) was quantified to be around $6.1 \mathrm{mmol} / \mathrm{g}$. This confirms the relatively high degree of HMDA binding to CNF-ald, which is preferentially a one-side (grafting) and rarely both-sides (crosslinking) reaction, being also supported by the good dispersibility of CNF-ald in aqueous media, although the attached HMDA resulted in the formation of CNF-HMDA aggregates, as revealed by the SEM images (Fig. 2).

The Zeta-Potential (ZP) values and the size distribution of CNF-HMDA in different media, presented in modification principles (Jin et al, 2015; Liimatainen et al. 2012), and visualized by SEM images

Fig. 3, clearly indicate an increase of $\mathrm{ZP}$ from about $+18 \mathrm{mV}$ (in absolute water) to about +20 to $+30 \mathrm{mV}$ (in the case of ethanol addition from 12 to $50 \%$, respectively) and its inversely proportional behavior in the case of acetone (from about $+35 \mathrm{mV}$ to $+33 \mathrm{mV}$ and $+18 \mathrm{mV}$ by addition of 12,25 and $50 \%$ of acetone, respectively), as well as the consequent increase or decrease of its average size distribution, being related to its aggregation phenomenon, as already discussed above. A better dispersion of the CNF-HMDA in a bipolar medium is attributed to the good compatibility of the hydrophobic ethylene groups from HMDA bound to the CNFs with ethanol/acetone and simultaneously ionized amino groups. However, the acetone, as a ketone without direct $\mathrm{OH}$ groups, cannot form hydrogen bonds and, 

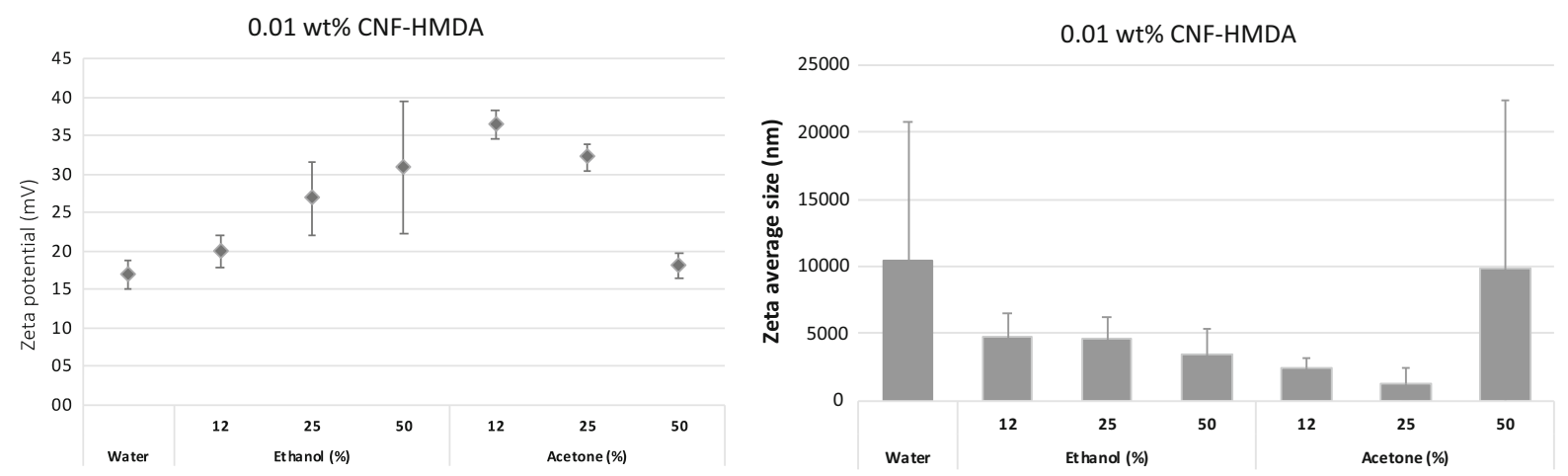

Fig. 3 Zeta Potential and average size distribution of $0.01 \mathrm{wt} \%$ CNF-HMDA in different aqueous media

thus, does not have the ability to attach to the functional groups of CNF-HMDA, as compared to the ethanol, which may, thus, also act as a better dispersing medium from the point of view of temporal stability.
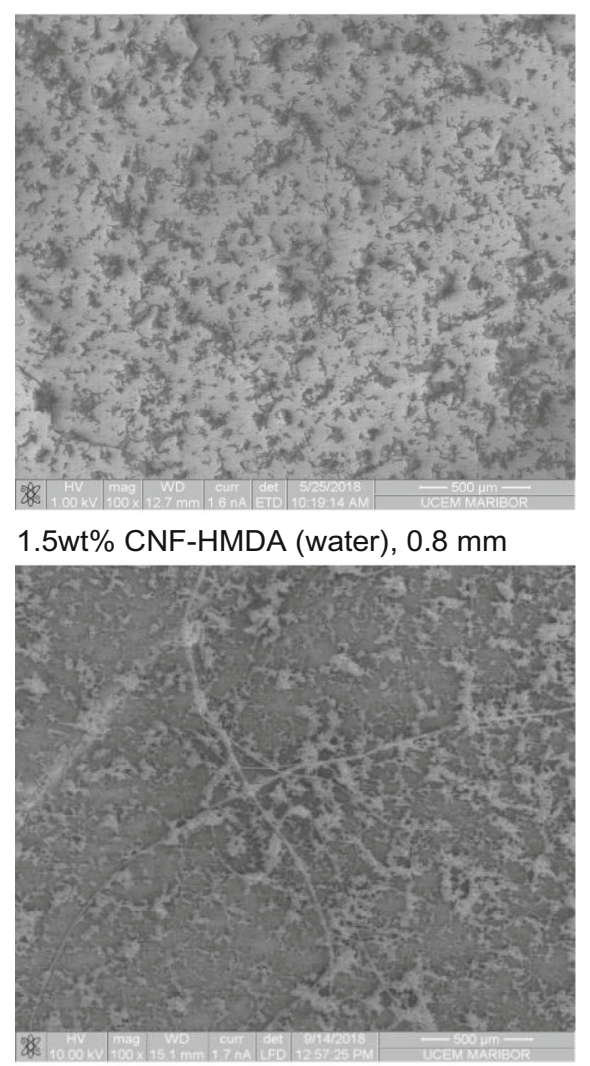

$3 w t \%$ CNF-HMDA (35\% ethanol), $0.4 \mathrm{~mm}$
The CNF-HMDA aqueous suspension deposition patterns, presented by the SEM imaging in Fig. 4, confirmed these findings by showing the difference in the amount and homogeneity of CNF-HMDA sprayed on aluminum foil by using different water mediums, as well as the ability to use lower nozzle-size openings

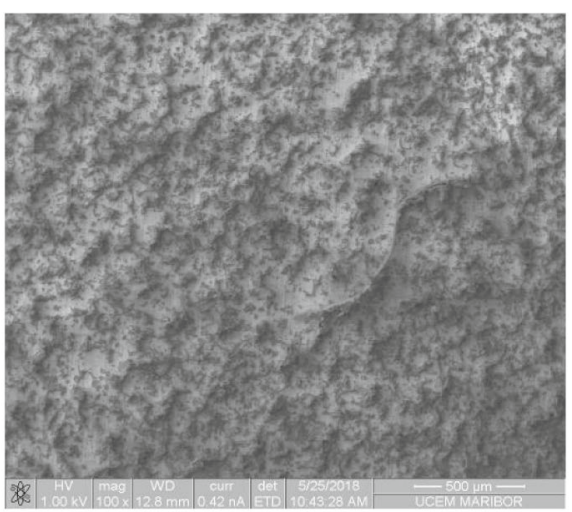

$3 w t \%$ CNF-HMDA (35\% acetone), $0.4 \mathrm{~mm}$

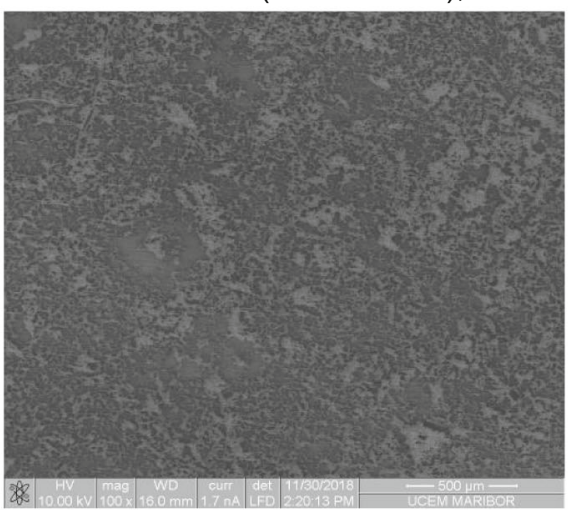

$5 \mathrm{wt} \%$ CNF-HMDA (35\% ethanol), $0.4 \mathrm{~mm}$

Fig. 4 SEM images of different CNF-HMDA suspensions sprayed to aluminum foil at $\sim 3$ bars of air and a distance of about $15 \mathrm{~cm}$ from the surface, using various nozzle sizes 
without their clogging. While $1.5 \mathrm{wt} \%$ was the highest concentration for water, suspended CNF-HMDA enabled its spraying with at least $0.8 \mathrm{~mm}$ nozzle openings; a bipolar water-acetone or water-ethanol medium enabled its spraying with up to $5 \mathrm{wt} \%$ concentrated CNF-HMDA and using nozzles with up to $0.4 \mathrm{~mm}$ size openings. As can be seen from the SEM images, the amount of CNF-HMDA deposition could be increased significantly, ensuring good dispersibility with relatively high homogeneity, among which water solutions with the addition of $25-35 \%$ ethanol or $12 \%$ acetone were selected as the optimal, and were used at the spray deposition of CNF-HMDA to the fiber sliver.

Chemical, wetting, structural and mechanical characteristics of CNF-HMDA integrated viscose yarns

The viscose slivers were sprayed with known amounts of differently concentrated and suspended CNFHMDA (Table 1), and air-dried before being ringspun into a functional yarn. The chemical (FTIR), surface (charge, hydrophilicity), wetting and structure-morphological properties, fineness and tenacity of the successfully spun viscose yarns were assessed to get information about the yarns" properties.

As can be seen from the results collected in Table 1 and presented graphically in Fig. 5, the spinning from the slivers sprayed with relatively low deposits (volume and conc.) of highly agglomerated watersuspended CNF-HMDA, and the use of the smallest $(0.8 \mathrm{~mm})$ nozzles to spray, resulted in a deposition of up to a max $132.5 \mathrm{mg} / \mathrm{g}$ (weight increase of 13.3\%) CNF-HMDA (Fig. 6), which, however, decreased the yarn's tenacity by about $30 \%$ (from 19.42 to $13.6 \mathrm{cN} /$ tex) and elongation at break by about $23 \%$ (from 14.4 to $11.1 \%$ ) according to the REF yarn. Comparatively, between $50-100 \mathrm{mg} / \mathrm{g}$ of CNFHMDA can be applied using $1 \mathrm{wt} \%$ of water suspended CNF-HMDA, without significant reduction of the yarn's mechanical properties. In contrast, a relatively higher amount of CNF-HMDA (up to $160 \mathrm{mg} / \mathrm{g}$, resulting in $16 \%$ of weight increase) could be integrated with CNF-HMDA suspended in $35 \%$ ethanol or acetone. In this case, the tenacity was reduced by about $19.6 \%$ (to $15.61 \mathrm{cN} /$ tex) and the elongation at break by about $7 \%$ (to $13.39 \%$ ), given less deviation when $5 \mathrm{wt} \%$ CNF-HMDA suspended in
$12 \%$ of acetone was used. Besides better dispersibility of CNF-HMDA among the fibers, faster drying kinetic of CNF-HMDA suspended in bi-polar mediums (where acetone evaporates even faster than ethanol despite its higher surface tension) during spraying, as compared to the absolute water, is, thus, another parameter reducing viscose fibers" gluing, and enabling smoother spinning, that gives a finer yarn (REF-acetone/ethanol) without affecting its tenacity. The reduction of both of these parameters in the case of CNF-HMDA functionalized yarns are, thus, the result of its concentration, integration and distribution among the fibers, as can be observed from the SEM images presented in Fig. 6.

The potentiometric titration curves of differently prepared yarns (Table 1), performed to follow the charge contribution from CNF-HMDA, follows the same, though much less intense, trend as pure CNFHMDA (Fig. 2). The values of total and amino functional groups were increasing with increasing of the CNF-HMDA content, given $\sim 0.079$ and $\sim$ $0.012 \mathrm{mmol} / \mathrm{g}$ (at $132.5 \mathrm{mg} / \mathrm{g}$ content), and even 0.663 and $\sim 0.439 \mathrm{mmol} / \mathrm{g}$ (at $160 \mathrm{mg} / \mathrm{g}$ content) of charges when sprayed from aqueous and faster evaporating aqueous-acetone mediums, respectively, and using the optimal spraying conditions (i.e. concentration of CNF-HMDA and nozzle size). The effect of washing resistance of such a yarn (Fig. 7), studied by 10 consecutive washings, showed that the use of detergent reduced the charge quantities significantly $(\sim 72 \%)$ (to $\sim 0.018$ and $\sim 0.01 \mathrm{mmol} / \mathrm{g}$ ), which was even more pronounced when the yarn was washed without it (to $\sim 0.084$ and $\sim 0.024 \mathrm{mmol} /$ g). The results indicate possible, preferably hydrophobic, interactions of surfactant molecules from the detergent with in-yarn surface integrated CNF-HMDA (as already confirmed in our other study, Vivod et al. 2019), which most likely prevented the excretion of CNF-HMDA from the yarn during washing as compared to washing it with pure water.

The FTIR spectra of viscose yarns prepared with and without the addition of CNF-HMDA, as well as after 10-times washing cycles performed with and without the addition of detergent, were performed, to identify its durability (Fig. 7). The spectrum for pure viscose yarn (d) shows a characteristic wide $\mathrm{O}-\mathrm{H}$ stretching band centered at around $3330 \mathrm{~cm}^{-1}, \mathrm{C}-\mathrm{H}$ stretching centered at around $2893 \mathrm{~cm}^{-1}$ and $\mathrm{C}-\mathrm{H}$ bending around 1460 and $1370 \mathrm{~cm}^{-1}$, an $\mathrm{H}-\mathrm{O}-\mathrm{H}$ 
Table 1 Properties of viscose yarns, ring-spun from fibrous slivers (of $1.2 \mathrm{kTex}$ ), sprayed with different CNF-HMDA suspensions

\begin{tabular}{|c|c|c|c|c|c|c|c|c|}
\hline \multirow[t]{2}{*}{ No. } & \multirow{2}{*}{$\begin{array}{l}\text { CNF- } \\
\text { HMDAa } \\
\text { suspension }\end{array}$} & \multicolumn{3}{|c|}{ Spraying of CNF-HMDA suspension } & \multicolumn{4}{|c|}{ Yarn properties } \\
\hline & & $\begin{array}{l}\text { Volume } \\
(\mathrm{mL})\end{array}$ & $\begin{array}{l}\text { Nozzles } \\
\text { size } \\
(\mathrm{mm})\end{array}$ & $\begin{array}{l}\text { Quantity (mg CNF- } \\
\text { HMDA/g viscose fibers) } \\
\text { (Weight increase, \%) }\end{array}$ & $\begin{array}{l}\text { Linear } \\
\text { density } \\
\text { Fitness } \\
(\mathrm{Nm})\end{array}$ & $\begin{array}{l}\text { Tenacity } \\
(\mathrm{cN} / \text { tex })\end{array}$ & $\begin{array}{l}\text { Elongation at } \\
\text { break }(\%)\end{array}$ & $\begin{array}{l}\text { Functional } \\
\text { groups }(\mathrm{mmol} / \\
\text { g) SD } 3-7 \%\end{array}$ \\
\hline 1 & REF & - & - & - & 24.6 & $19.42 \pm 0.60$ & $14.40 \pm 0.80$ & 0 \\
\hline 2 & $\begin{array}{l}\text { REF- } \\
\text { water }\end{array}$ & 100 & - & - & 20.4 & $17.22 \pm 0.70$ & $16.37 \pm 0.90$ & n.d \\
\hline 3 & $\begin{array}{c}\text { REF-25\% } \\
\text { acetone }\end{array}$ & 200 & 0.4 & - & 27.8 & $18.70 \pm 1.55$ & $15.71 \pm 1.39$ & n.d \\
\hline 4 & $\begin{array}{c}\text { REF-25\% } \\
\text { ethanol }\end{array}$ & 200 & 0.4 & - & 27.8 & $19.05 \pm 1.46$ & $15.41 \pm 1.18$ & n.d \\
\hline 5 & $1 \mathrm{wt} \%$ & 150 & 0.8 & $50 \mathrm{mg} / \mathrm{g}(+5 \%)$ & 17.9 & $13.98 \pm 0.99$ & $13.70 \pm 1.10$ & n.d \\
\hline 6 & & 200 & 0.8 & $66.7 \mathrm{mg} / \mathrm{g}(+6.7 \%)$ & 19.2 & $16.64 \pm 0.90$ & $15.26 \pm 0.93$ & n.d \\
\hline 7 & & 300 & 0.8 & $100 \mathrm{mg} / \mathrm{g}(+10 \%)$ & 20.0 & $15.57 \pm 0.85$ & $14.06 \pm 0.99$ & $\begin{array}{l}\text { Total: } 0.117 \\
\text { Amino:0 }\end{array}$ \\
\hline 8 & $\begin{array}{r}1.5 \mathrm{wt} \% \\
\text { (water) }\end{array}$ & 265 & 0.8 & $132.5 \mathrm{mg} / \mathrm{g}(+13.3 \%)$ & 22.2 & $13.6 \pm 1.84$ & $11.44 \pm 2.10$ & $\begin{array}{l}\text { Total: } 0.079 \\
\text { Amino: } 0.014\end{array}$ \\
\hline 9 & $\begin{array}{l}3 \mathrm{wt} \% \\
(35 \% \\
\text { ethanol) }\end{array}$ & 160 & 0.4 & $160 \mathrm{mg} / \mathrm{g}(+16 \%)$ & 21.9 & $15.61 \pm 0.96$ & $13.93 \pm 0.77$ & $\begin{array}{l}\text { Total: } 0.066 \\
\text { Amino: } 0.014\end{array}$ \\
\hline 10 & $\begin{array}{l}3 \mathrm{wt} \% \\
(35 \% \\
\text { acetone) }\end{array}$ & 160 & 0.4 & $160 \mathrm{mg} / \mathrm{g}(+16 \%)$ & 21.9 & $15.61 \pm 0.96$ & $13.93 \pm 0.77$ & $\begin{array}{l}\text { Total: } 0.663 \\
\text { Amino: } 0.439\end{array}$ \\
\hline 11 & $5 \mathrm{wt} \%$ & 80 & 0.4 & $133 \mathrm{mg} / \mathrm{g}(+13.3 \%)$ & 22.2 & $14.11 \pm 1.01$ & $14.62 \pm 1.58$ & $\begin{array}{l}\text { Total: } 0.059 \\
\text { Amino: } 0.017\end{array}$ \\
\hline 12 & & 60 & 0.4 & $100 \mathrm{mg} / \mathrm{g}(+10 \%)$ & 20.5 & $17.43 \pm 1.13$ & $15.43 \pm 1.08$ & $\begin{array}{l}\text { Total: } 0.052 \\
\text { Amino: } 0.012\end{array}$ \\
\hline 13 & & 40 & 0.4 & $66.7 \mathrm{mg} / \mathrm{g}(+6.7 \%)$ & 20.0 & $15.84 \pm 1.07$ & $16.09 \pm 0.79$ & $\begin{array}{l}\text { Total: } 0.056 \\
\text { Amino: } 0.007\end{array}$ \\
\hline 14 & & 20 & 0.4 & $33.3 \mathrm{mg} / \mathrm{g}(+3.3 \%)$ & 21.0 & $17.43 \pm 1.14$ & $16.55 \pm 0.72$ & $\begin{array}{l}\text { Total: } 0.041 \\
\text { Amino: } 0.017\end{array}$ \\
\hline
\end{tabular}

bending band of absorbed water at around $1638 \mathrm{~cm}^{-1}$, and strong $\mathrm{C}-\mathrm{O}-\mathrm{C}$ stretching vibrations' band of the glucoside ring in the spectral region ranging from $1150 \mathrm{~cm}^{-1}$ to $800 \mathrm{~cm}^{-1}$ representing the fingerprint of the cellulose (Peets et al. 2019). A decrease of intensity of $\mathrm{O}-\mathrm{H}$ stretching and $\mathrm{C}-\mathrm{O}$ stretching bands and their shifting to about $3304 \mathrm{~cm}^{-1}$ and $1032 \mathrm{~cm}^{-1}$, respectively, the splitting of the $\mathrm{C}-\mathrm{H}$ band to asymmetric and symmetric stretchable $\mathrm{CH}_{2}$ vibrations (at around $2925 \mathrm{~cm}^{-1}$ and $2857 \mathrm{~cm}^{-1}$ ) with the appearance of symmetrical $\mathrm{CH}_{2}$ bending and $\mathrm{CH}_{2}$ wagging vibrations at about $1459 \mathrm{~cm}^{-1}$ and $1314 \mathrm{~cm}^{-1}$, respectively, all corresponding to the methyl chains from HMDA. The appearance of $\mathrm{N}-\mathrm{H}$ bending vibrations for amino groups in the region of $1540-1580 \mathrm{~cm}^{-1}$, can be also observed in the yarn with integrated CNF-HMDA (a), which supports the fact of CNF-HMDA integration, as well as its interactions with the cellulose units of viscose by the creation of new inter- and intramolecular hydrogen bonds (Vivod et al. 2019). The HMDA assigned bands in the case of washed yarns ( $b$ and $c$ ) were reduced, while cellulose $(\mathrm{O}-\mathrm{H}, \mathrm{C}-\mathrm{H}$ and $\mathrm{C}-\mathrm{O})$ related bands were increased, the effect being more pronounced when using detergent (c). 


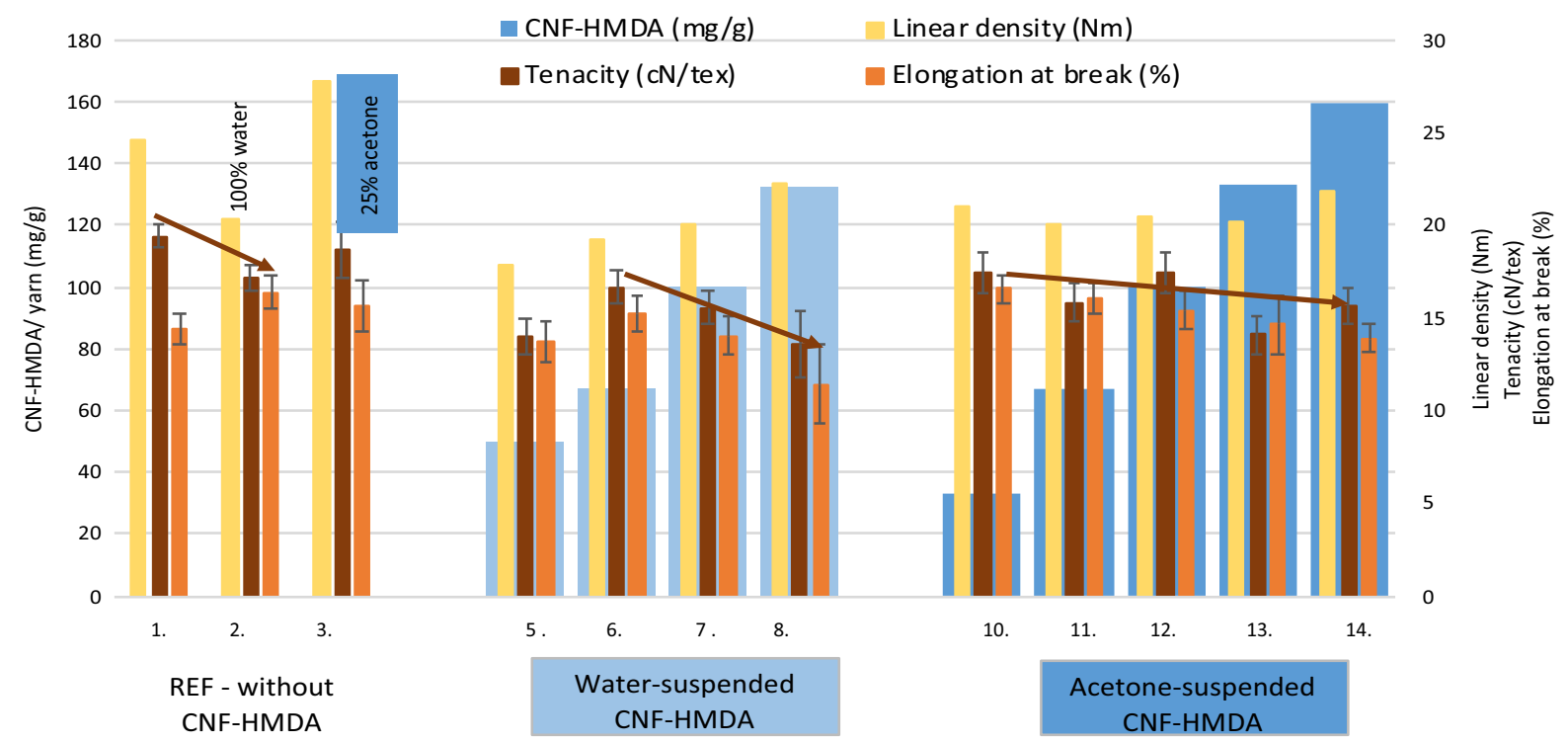

Fig. 5 Linear density, tenacity and elongation at break of viscose yarns, ring-spun from fiber slivers, sprayed with different CNFHMDA suspensions; the numbering follows that in Table 1
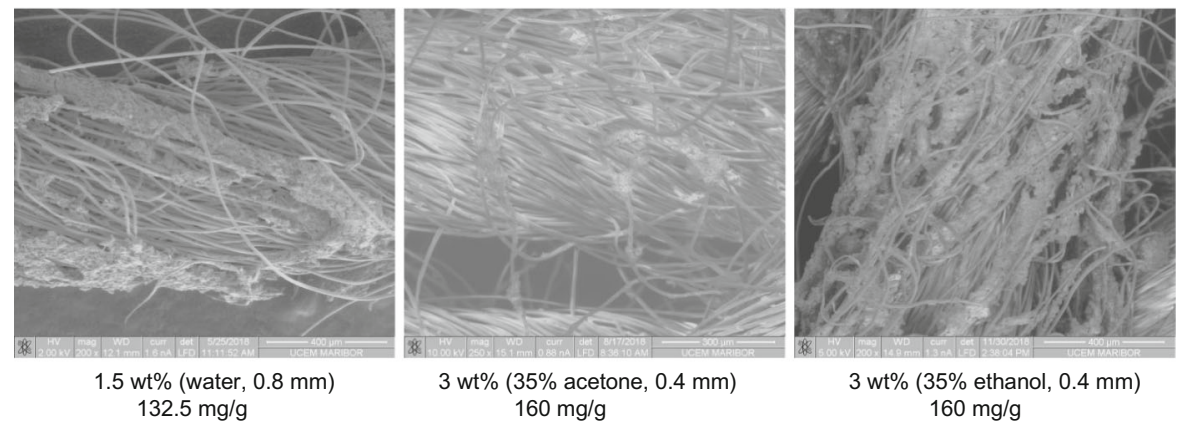

Fig. 6 SEM images of yarns spun from slivers with differently sprayed CNF-HMDA suspensions

The wettability of differently prepared yarns, studied by the kinetic of milliQ water absorbency and its capacity (Fig. 8), also exhibited a corresponding dependency on the yarns " preparation, correlated well with the results of titration and spectroscopy analysis. It is well-known that the wettability of the fibers is induced by the hydrogen bonding capability with the liquid, thus depending on its surface properties (charge, hydrophobicity), crystallinity structure and density of the fibers, as well as the temperature and $\mathrm{pH}$ of the liquid. The absorbency curve of the reference yarn sample (with no CNF-HDMA content) showed the slowest absorbency rate, meaning that this sample needed the longest period for establishing the equilibrium (i.e. $120 \mathrm{~s}$ ), while the amount of absorbed
milliQ was the highest $(\sim 1.67 \mathrm{~g} / \mathrm{g}$ of dry sample, inserted Table) compared to the CNF-HDMA integrated yarns. Contrarily, the yarn containing the highest $(160 \mathrm{mg} / \mathrm{g})$ amount of CNF-HDMA, showed the highest aborbency velocity (indicated by the steeper curve), since the equilibrium was established in the shortest time $(\sim 40 \mathrm{~s})$ compared to the other samples containing CNF-HMDA (43-58 s), but it had the lowest value of adsorbency $(\sim 1.53 \mathrm{~g} / \mathrm{g})$. The other samples (containing 33.3, 66.7, 100, and $133 \mathrm{mg} / \mathrm{g}$ CNF-HDMA) showed more or less similar wetting behavior, i.e. similar absorbency velocity, while absorbing bewteen 1.66 and $1.53 \mathrm{~g} / \mathrm{g}$ of milliQ water. On the other hand, the reference sample showed the highest Contact Angle $\left(\mathrm{CA}, \sim 88.8^{\circ}\right.$ ), while the 


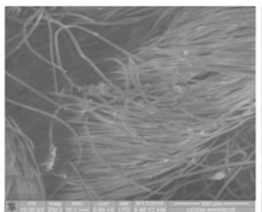
b) $10 \times$ washed without

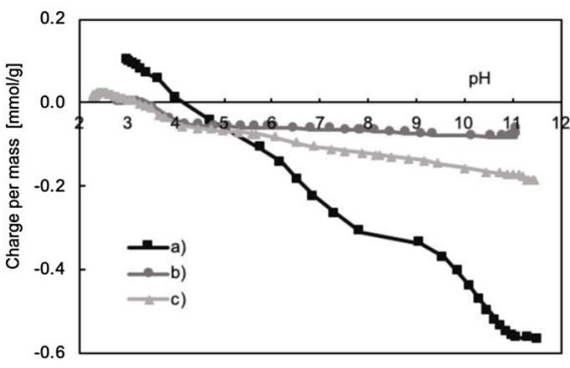

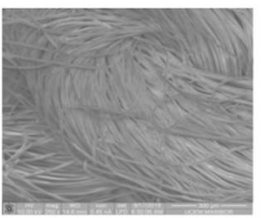

c) 10x washed with detergent

\begin{tabular}{|l|l|c|c|c|c|c|c|c|}
\hline & $\begin{array}{l}\text { Yarn with 160 mg/g } \\
\text { of CNF-HMDA }\end{array}$ & $\mathrm{pK} 1$ & $\begin{array}{c}\text { Charge pK1 } \\
(\mathrm{mmol} / \mathrm{g})\end{array}$ & $\mathrm{pK} 2$ & $\begin{array}{c}\text { Charge pK2 } \\
(\mathrm{mmol} / \mathrm{g})\end{array}$ & $\mathrm{pK} 3$ & $\begin{array}{c}\text { Charge pK3 } \\
(\mathrm{mmol} / \mathrm{g})\end{array}$ & $\begin{array}{c}\text { Charge } \\
\text { TOTAL } \\
(\mathrm{mmol} / \mathrm{g})\end{array}$ \\
\hline a) & Unwashed & 3.9 & 0.224 & 6.6 & 0.228 & 10 & 0.211 & 0.663 \\
\hline b) & $\begin{array}{l}\text { 10x washed without } \\
\text { detergent }\end{array}$ & 3.7 & 0.060 & 6.5 & 0.006 & 8.7 & 0.018 & 0.084 \\
\hline c) & $\begin{array}{l}\text { 10x washed with } \\
\text { detergent }\end{array}$ & 3.7 & 0.080 & 6.6 & 0.053 & 9.6 & 0.051 & 0.184 \\
\hline
\end{tabular}

Fig. 7 Potentiometric titration curves (left) with corresponding charges (inserted Table, SD 3-7\%) and FTIR spectra (right) of viscose yarns prepared with $160 \mathrm{mg} / \mathrm{g}$ of CNF-HMDA (using $160 \mathrm{~mL}$ of $3 \mathrm{wt} \%$ CNF-HMDA suspended in 35\% acetone) a Before and after 10-cycle washing $\mathbf{b}$ Without and $\mathbf{c}$ With the

amount of added CNF-HDMA decreased the CA values from $\sim 87.8^{\circ}$ to $\sim 73.3^{\circ}$, being the lowest for the sample containing the highest amount of CNFHDMA (160 mg/g), and which can be described as the most surface hydrophilic, given the highest aborbency velocity. As the CA depends on the difference between the surface tension of the material and the surface tension of the liquid (in our case water with very high surface tension, $\sim 72.8 \mathrm{mN} / \mathrm{m}$ ), and the adsorption depends on the difference between them (i.e. the greater the difference between surface tensions, the lower is the adsorption), we can concude that the addition of CNF-HDMA (bearing highly polar amino groups) to viscose yarn contributed importantly to its wettability.

It is obvious that CNF-HMDA functionalized viscose yarn absorbs milliQ water kinetically faster compared to the pure viscose yarn, which may be addition of detergent, respectively, visualized by SEM imaging. The spectra of the reference yarns, 10-cycle washed d Without and $\mathbf{e}$ With detergent, are also added to the graph of the FTIR spectra

related to the presence of amino functional groups, which, next to the free hydroxylic groups arising from $\mathrm{CNF}$, enchanced the yarn's surface hydrophilicity (being seen in the relatively lower CA values), and, thus, faster hydration of the surface. However, on the other hand, the water's absorption ability was decreased quantitatively by increasing the CNFHMDA content, which can be due to various reasons. Deprotonated CNF-HMDA's amino groups may mitigate the electrostatic repulsion with the present rare anionized sulpho- and carboxylic- groups at CNF, and with the presence of hydrophobic interactions between the alkyl chains of the HMDA, reducing the reactive groups coming into contact with water molecules and reducing or deswelling the yarn. The effect of the CNF-HMDA present, i.e. its orientation and distribution through the yarn, is also reflected in the yarn's morphological structure (i.e. a more open yarn 
Fig. 8 The absorbency rate with corresponding aborbency capacity and Contact Angle (CA) values of viscose yarn prepared without (REF) and with different content of CNFHMDA, being 10-cycles washed using milliQ water

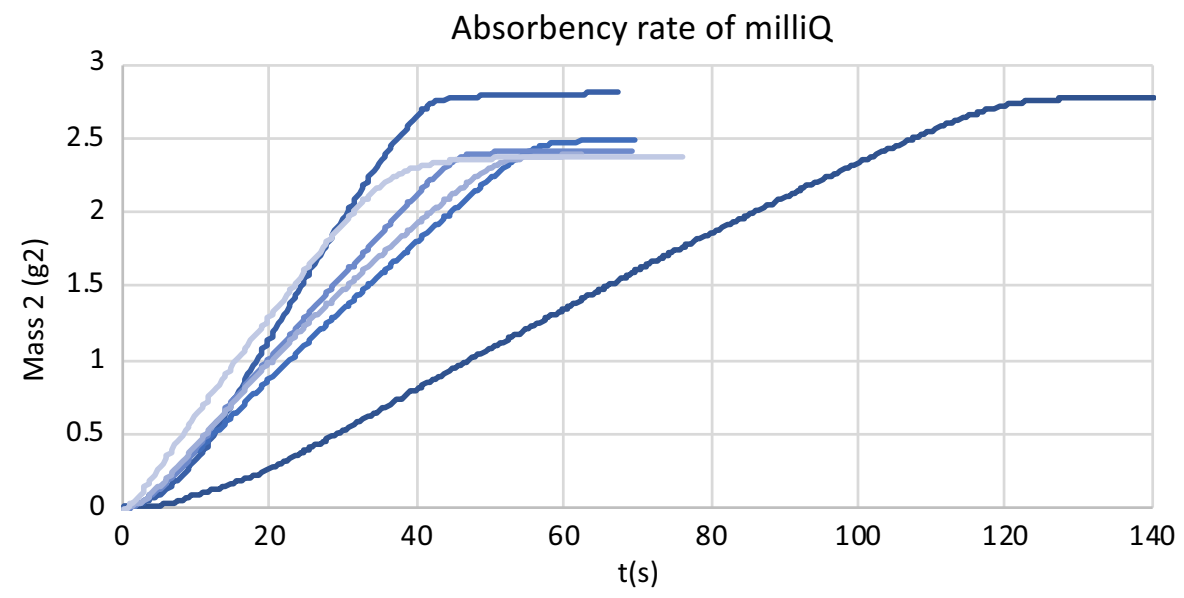

- REF $-33.3 \mathrm{mg} / \mathrm{g}-66.7 \mathrm{mg} / \mathrm{g}=100 \mathrm{mg} / \mathrm{g}=133 \mathrm{mg} / \mathrm{g}=160 \mathrm{mg} / \mathrm{g}$

\begin{tabular}{|c|c|c|}
\hline $\begin{array}{c}\text { CNF-HMDA } \\
\text { content }\end{array}$ & $\begin{array}{c}\text { milliQ/g } \\
(\mathrm{g})\end{array}$ & $\begin{array}{c}\text { Contact Angle } \\
\left({ }^{\circ}\right)\end{array}$ \\
\hline $\mathrm{REF}$ & $1.6712 \pm 0.0144$ & $88.8 \pm 0.60$ \\
\hline $33.3 \mathrm{mg} / \mathrm{g}$ & $1.6643 \pm 0.0476$ & $87.8 \pm 0.81$ \\
\hline $66.7 \mathrm{mg} / \mathrm{g}$ & $1.5768 \pm 0.0378$ & $87.8 \pm 0.12$ \\
\hline $100 \mathrm{mg} / \mathrm{g}$ & $1.5438 \pm 0.0157$ & $86.9 \pm 0.35$ \\
\hline $133 \mathrm{mg} / \mathrm{g}$ & $1.5365 \pm 0.0150$ & $86.8 \pm 0.28$ \\
\hline $160 \mathrm{mg} / \mathrm{g}$ & $1.5391 \pm 0.0102$ & $73.3 \pm 1.34$ \\
\hline
\end{tabular}

structure with less densely packed and oriented viscose fibers, which can be seen on the SEM images presented in Fig. 6), and reduced fineness (Table 1, Fig. 5), which also influenced the CA values, suggesting that pure viscose yarn is less hydrophilic in nature compared to the yarns containing CNF-HMDA.

Antimicrobial activity of CNF-HMDA integrated viscose yarns

The antimicrobial activity of CNF-HMDA suspension and CNF-HMDA integrated viscose yarns was assessed using different methods in order to define their efficacy under different conditions.

The Minimal Inhibitory Concentration (MIC) of CNF and CNF-HMDA suspensions was tested first. The CNFs cannot target and disturb the cell wall, cell membrane, or active enzymes of bacterial and fungal strains, so haven't shown any antimicrobial activity. However, HDMA functionalized CNFs exhibited good antibacterial and antifungal effects against all selected microorganisms associated with inflammatory-related skin diseases: Gram-positive bacterial $(\mathrm{G}+)$ S. aureus, Gram-negative (G-) bacteria E. coli, and skin fungus $C$. albicans, given MIC of $\sim 0.012$ $\mathrm{wt} \%, \sim 0.193 \mathrm{wt} \%$ and $\sim 0.024 \mathrm{wt} \%$, respectively. Besides of a hydrophobic tail, the contact of amino groups might, namely, play an essential role in the antimicrobial activity, which is related to the positively charged cationic nature (Fig. 2), leading to an increase in the chance of the interaction with the negatively charged cell walls of the microorganisms.

The ability of CNF-HMDA suspension and (133 mg/g) CNF-HMDA integrated viscose yarns (washed and 10-cycles washed without detergent) to inhibit selected bacterial growth after $24 \mathrm{~h}$ of 
incubation was tested by the agar diffusion method and using both bacteria. The results, presented on Fig. 9, showed a clear zone of inhibition around the highly-concentrated suspension of CNF-HMDA, as well as viscose yarns containing CNF-HMDA, with no bacterial growth on and under the yarns ' top surfaces, while the control yarn showed no sign of inhibition. The inhibitory effect of CNF-HMDA suspension was, in diameter, higher against $S$. aureus $(\sim 8 \mathrm{~mm})$ compared to $E$. coli $(\sim 10 \mathrm{~mm})$, while the yarns showed a slightly different effect $(\sim 14 \mathrm{~mm}$ of inhibition for $S$. aureus and $\sim 16 \mathrm{~mm}$ for E. coli) being more pronounced but less effective $(\sim 13$ and $\sim 15 \mathrm{~mm}$, respectively) for the 10-cycles washed samples. Although this testing indicated that samples have an antimicrobial activity potential, it only implied that bacteria have been prevented from growing on the yarn surfaces (i.e. by contact), and potentially, also due to the slow release of CNFHMDA onto the fiber surface and/or from the surface during incubation (i.e. by diffusion).

In order to get information on the surface-adsorption ability effect on the microorganisms ' inhibition, the samples were incubated at different time-intervals (1-6 h) and the percent of their reduction (R, \%) was evaluated, as well as the reduction factor $(\log R)$. As seen from the Fig. $10 \mathrm{a}-\mathrm{c}$, an increased content of
CNF-HMDA in the yarn increased bacteria reduction, although it also gave different effects depending on the microbial profile. The powerful effect of CNF-HMDA functionalized yarn on the Gram-positive $S$. aureus rather than the Gram-negative E. coli bacterium may be due to the difference in the composition of the cell wall on the one hand, and the effect of the surface charge (amination and overall hydrophilicity) of the yarn on the other. Gram-negative bacteria have a thick layer of phospholipids rather than peptidoglycans when compared to Gram-positive bacteria, which have a thick layer of peptidoglycans. The negative charge on the phospholipids have, thus, enhanced the adhesion power of the polycationic polymer of the cell wall. A slightly smaller effect on the antimicrobial activity for E.coli could, thus, be explained by an increase in the distance between the attached amino groups and the CNF backbone (Mohy Eldin et al. 2012), which, however, still yielded the 80-99\% reduction of bacteria within 1-3 h at the highest CNFHMDA content $(133 \mathrm{mg} / \mathrm{g})$, and a given $\log$ reduction in between 0.69-2.95. A similar effect on the reduction of S.aureus was obtained by using a yarn containing only $33 \mathrm{mg} / \mathrm{g}$ of CNF-HMDA, while its further increase already reduced the $\log$ reduction significantly to a value of around 4.0 within $3 \mathrm{~h}$.
Fig. 9 Zone of inhibition $(\mathrm{mm})$ against tested bacteria for $3.2 \mathrm{wt} \%$ CNF-HMDA suspension and viscose yarns containing $133 \mathrm{mg} / \mathrm{g}$ of CNF-HMDA, before and after 10-cycles washing without detergent. The photos were taken on the bottom side of the Petri dish
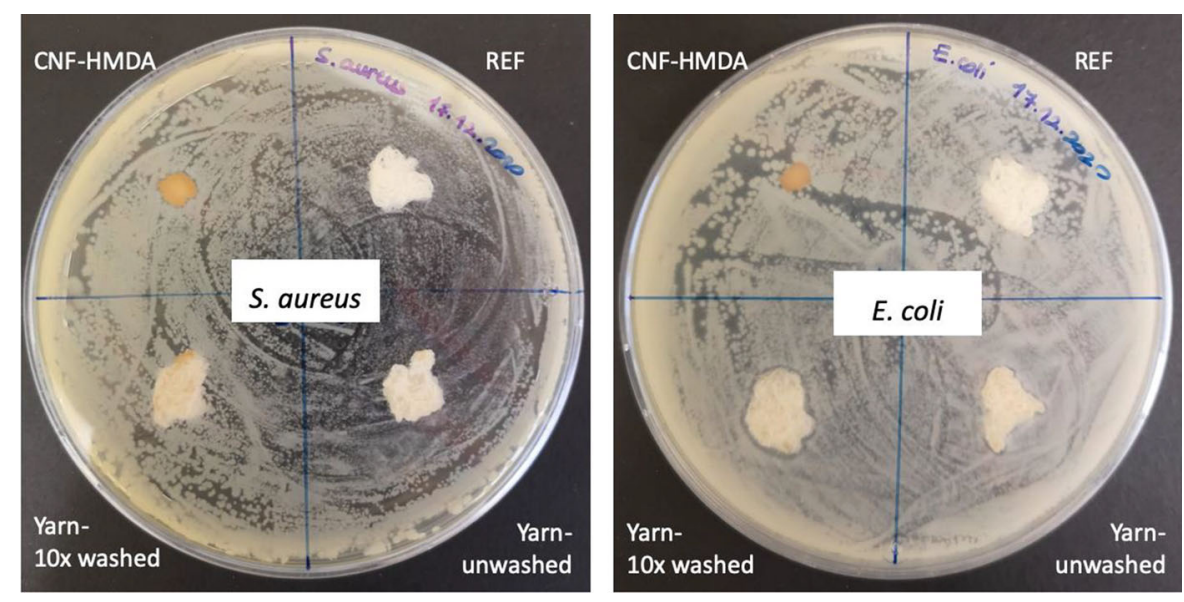

\begin{tabular}{|l|c|c|}
\hline \multirow{2}{*}{ Sample } & \multicolumn{2}{|c|}{ Zone of inhinition (mm) } \\
\cline { 2 - 3 } & S. aureus $(\mathrm{G}+)$ & E. coli $(\mathrm{G}-)$ \\
\hline Yarn-REF & 0 & 0 \\
\hline $3.2 \mathrm{wt} \%$ CNF-HMDA suspension & $10 \pm 0.5$ & $8 \pm 0.5$ \\
\hline Yarn with CNF-HMDA - unwashed & $14 \pm 1.7$ & $16 \pm 1.7$ \\
\hline Yarn with CNF-HMDA - 10x washed & $11 \pm 1.5$ & $15 \pm 1.7$ \\
\hline
\end{tabular}


S. aureus $(G+)$

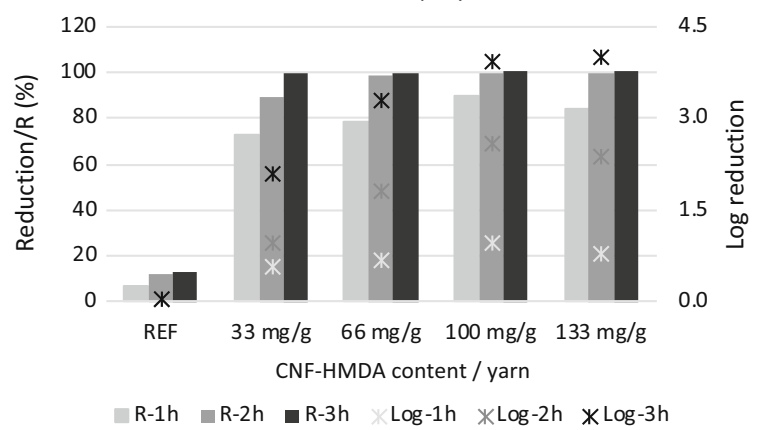

(a)

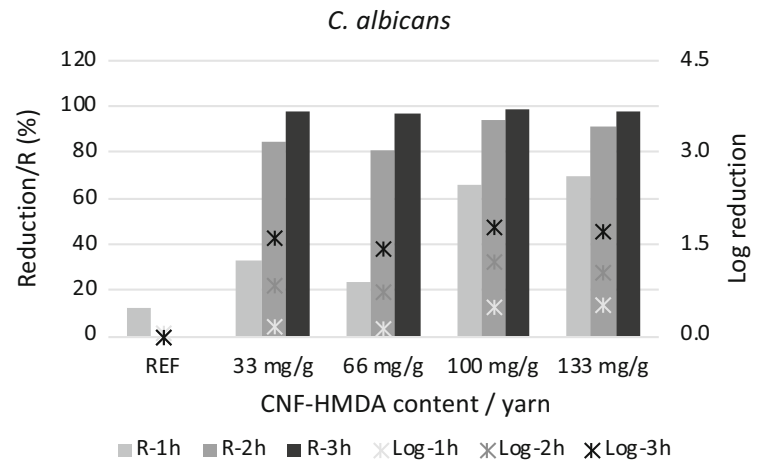

(c)

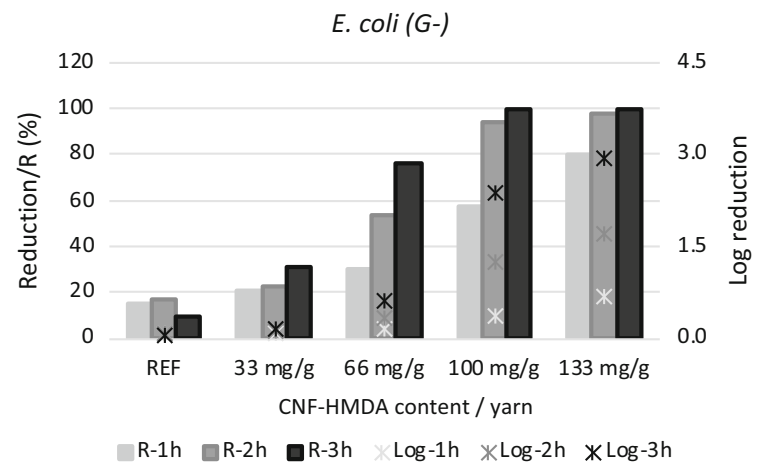

(b)

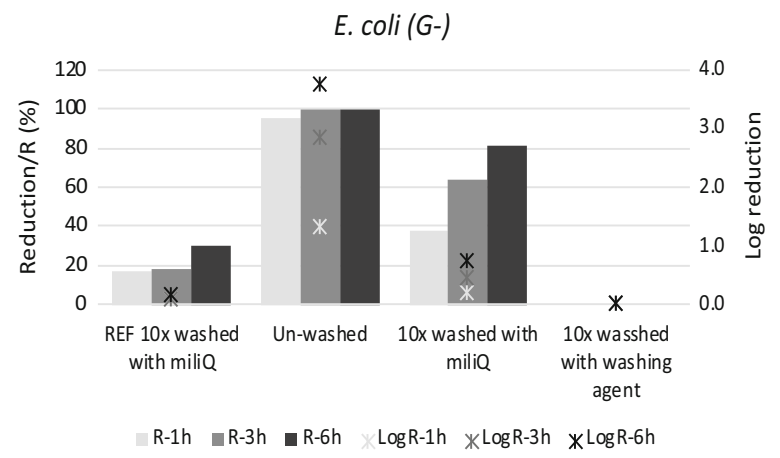

(d)

Fig. 10 The effect of a-c CNF-HMDA content $(0-133 \mathrm{mg} / \mathrm{g})$ and $\mathbf{d}$ The washing procedure $(160 \mathrm{mg} / \mathrm{g})$ on the antimicrobial activity of viscose yarn against different microorganisms, relative to the yarn-free bacterial suspension

The durability of the yarn's antibacterial effect after washing was also performed using yarn functionalized with $160 \mathrm{mg} / \mathrm{g}$ of CNF-HMDA, before and after 10-cycles washing being performed, with and without detergent. As shown in Fig. 10 d, the functionalized yarn still provided up to $80 \%$ reduction of $E$. coli after 10 -cycles of washing without detergent, while showing no effect in the case of its washing in the presence of detergent. This may be due to the presence of the residues of non-ionic surfactants on the yarn surface after washing (Kaisersberger-Vincek et al. 2017), which are interacting hydrophobically with the hydrophobic sites of HMDA, thus blocking its functional amino groups. This fact can be supported by the washing of unfunctionalized yarn with the surfactant, showing a small reduction of bacteria, indicating that CNF-HMDA inhibits the growth of bacteria in contact with the surface.

The bactericidal effect, determined after $24 \mathrm{~h}$ of yarns' incubation, coincides with the above findings. The data inserted in the graphs in Fig. 11 show an increase in bactericidal effect as a result of the relative decrease in green fluorescence intensity when yarn was functionalized with $133 \mathrm{mg} / \mathrm{g}$ of CNF-HMDA. These values for Gram-positive $S$. aureus were comparatively higher ( $\sim 45 \%$ for both unwashed and 10-times washed) than those for Gram-negative E. coli bacterium (given $\sim 21 \%$ for unwashed sample only), while showing no effect in the case of the reference samples (without CNF-HMDA content). However, as already pointed out in one of our previous studies (Kaisersberger-Vincek et al, 2017), these results need a critical evaluation, due an in-effective staining of some intact Gram-negative bacteria with SYTO9, being related to its permeability problems through the double-membrane layer or its exporting from the bacteria cytoplasm, as well as a decrease in green fluorescence intensity due to the entrance of PI.

The confocal fluorescence microscopy imaging of the yarn samples was also performed, despite the fact that the combined fluorescent staining may lead to results with some deviations, above all as the viscose 

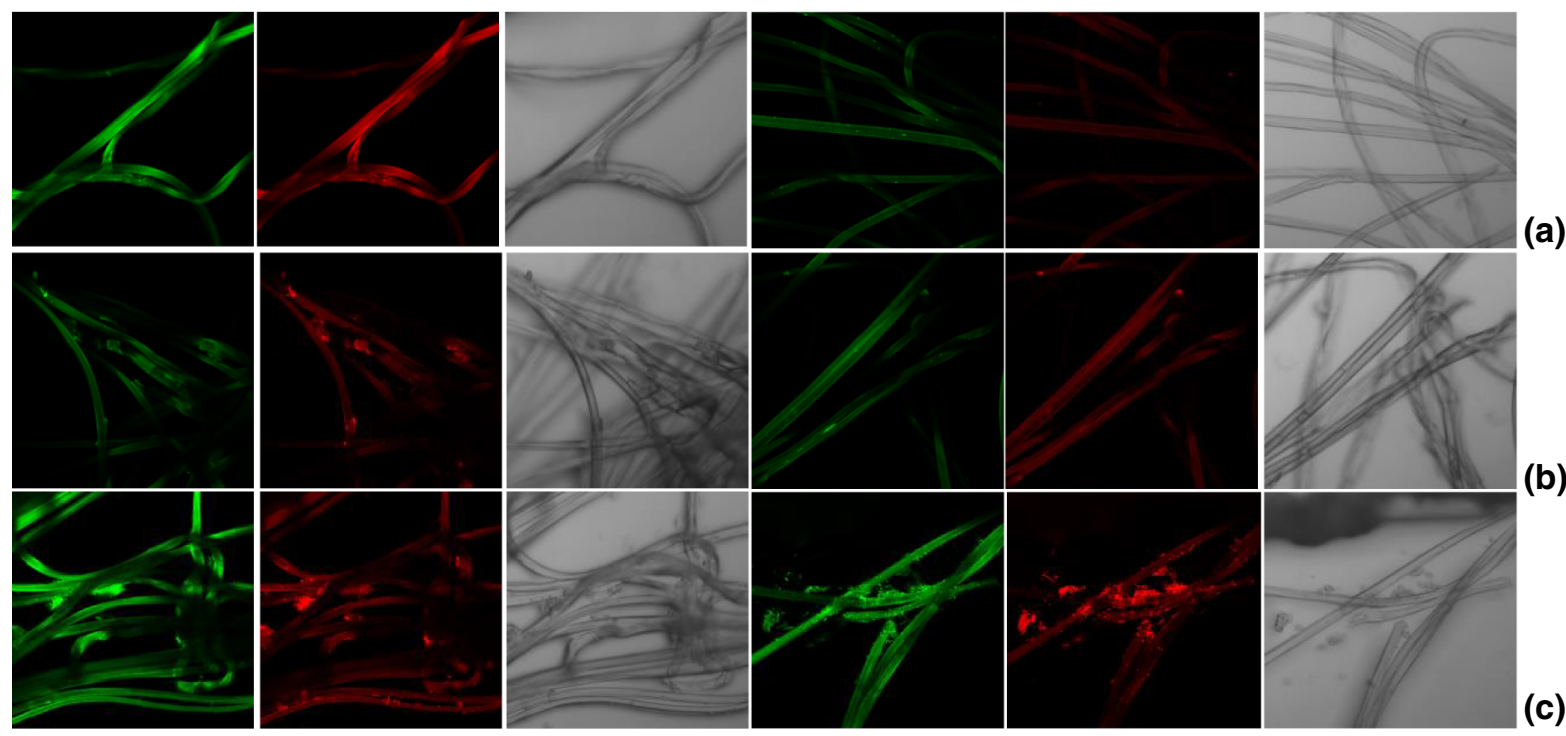

S. aureus $\left(\mathrm{G}^{+}\right)$

E. $\operatorname{coli}(\mathrm{G}-)$

\begin{tabular}{|l|c|c|}
\hline \multirow{2}{*}{ Sample } & \multicolumn{2}{|c|}{ Bactericidal effect (\%) } \\
\cline { 2 - 3 } & S. aureus $(\mathrm{G}+)$ & E. coli $(\mathrm{G}-)$ \\
\hline Yarn-REF & $2 \pm 1$ & $1 \pm 1$ \\
\hline Yarn with CNF-HMDA - unwashed & $45 \pm 3$ & $21 \pm 3$ \\
\hline Yarn with CNF-HMDA - 10x washed & $45 \pm 1$ & $1 \pm 1$ \\
\hline
\end{tabular}

Fig. 11 Confocal microscopy images and Bactericidal effect (inserted Table) of the CNF-HMDA functionalized $(133 \mathrm{mg} / \mathrm{g}$ ) yarn samples, unwashed $\mathbf{b}$ and washed $\mathbf{c}$ 10-cycles washing without detergent, in comparison with the reference sample a, after exposure to a medium inoculated with gram-positive $S$.

fibers themselves were also colorized. In Fig. 11, the presented representative fluorescence images after exposure to the bacteria show green labeled cells on the surface of all the tested samples, being more intensive on the reference sample when compared to the yarns containing CNF-HMDA, where the presence of a high density of red bacteria (above all in the case of $S$. aureus) indicates that CNF-HMDA may interact with bacteria' cytoplasmic membranes. A diffusion of the CNF-HMDA from the yarn on its surface may be also seen on the washed samples.

\section{Conclusion}

The cellulose nanofibrils (CNFs) were functionalized with hexamethylenediamine (HMDA), and used as aureus and gram-negative E. coli or for $24 \mathrm{~h}$, and a Live/Dead BacLight bacterial viability staining test. Representative scans were taken at $20 \times$ magnification, showing a green color for Live and a red color for Dead bacterial cells; uniform staining was also observed of the viscose fibers

skin non-irritating, but highly antimicrobially active, additives (with Minimum Inhibitory Concentrations of 0.012-0.193 wt \%) to a ring-spun viscose yarn, applied by spraying onto a viscose fiber sliver before the spinning. The dispersibility and suspensibility of CNF-HMDA in different media were studied to optimize its sprayability with the lowest sticking phenomena of the fibers, enable its spinning without flowing and tearing problems. The CNF-HMDA was applied the most homogeneously when sprayed from a highly concentrated $(5 \mathrm{wt} \%)$ and fast-evaporated bipolar aqueous medium using a smaller nozzle size (0.4 mm), thus giving evenly distributed CNF-HMDA with well acessable amino groups, without affecting the yarn's tenacity and fineness. The yarn's antimicrobial activity was increasing with the content of CNF-HMDA, given a 99\% reduction for Gram- 
positive bacteria $S$. aureus and fungus $C$. albicans in up to $3 \mathrm{~h}$ at a minimum $33 \mathrm{mg} / \mathrm{g}$ of CNF-HMDA content, while a minimum $100 \mathrm{mg} / \mathrm{g}$ of its addition was required for reduction of Gram-negative E. coli. However, both bacteria were yielding high (up to 4.0) $\log$ reduction value, and exhibiting adequate bactericidal properties $(25-45 \%)$. In addition, the durability of CNF-HMDA functionalized yarn to washing using non-ionic surfactant was shown to reduce the yarn's antimicrobial properties, due to its adsorbtion via the methylene chain of HMDA, thereby blocking its amino groups, and, thus, preventing its interaction with bacteria, although being much less affected in the case when the washing was carried out without surfactant. This work brought new knowledge into the designing of bio-based, non-toxic and biodegradable antimicrobially active textiles using renewable nanomaterials and conventional technological processes, thus offering the potential for creating many multifunctional or specific protections.

Funding The work was carried out within the project Cel.Cycle:»Potential of biomass for development of advanced materials and bio-based products« (Contract no. OP20.00365), co-financed by the Republic of Slovenia, Ministry of Education, Science and Sport and the European Union under the European Regional Development Fund.

\section{Declarations}

Conflict of interest The authors declare that they have no conflicts of interest to reveal.

Open Access This article is licensed under a Creative Commons Attribution 4.0 International License, which permits use, sharing, adaptation, distribution and reproduction in any medium or format, as long as you give appropriate credit to the original author(s) and the source, provide a link to the Creative Commons licence, and indicate if changes were made. The images or other third party material in this article are included in the article's Creative Commons licence, unless indicated otherwise in a credit line to the material. If material is not included in the article's Creative Commons licence and your intended use is not permitted by statutory regulation or exceeds the permitted use, you will need to obtain permission directly from the copyright holder. To view a copy of this licence, visit http://creativecommons.org/licenses/by/4.0/.

\section{References}

Abitbol T, Rivkin A, Cao Y, Nevo Y, Abraham E, Ben-Shalom T, Lapidot S, Shoseyov O (2016) Nanocellulose, a tiny fiber with huge applications. Curr Opin Biotechnol 39:76-88. https://doi.org/10.1016/j.copbio.2016.01.002

Adams LK, Lyon DY, Alvarez PJJ (2006) Comparative ecotoxicity of nanoscale $\mathrm{TiO} 2, \mathrm{SiO} 2$, and $\mathrm{ZnO}$ water suspensions. Water Res 40(19):3527-3532. https://doi.org/10. 1016/j.watres.2006.08.004

Agarwal SR, Sundarrajan S, Venkatesan A, Ramakrishna S (2012) One-step synthesis of hollow titanate ceramic fibers for detoxification of nerve agents. $\mathrm{J}$ Nanotech 2012:429021. https://doi.org/10.1155/2012/429021

Alam MN, Christopher LP (2017) A novel, cost-effective and eco-friendly method for preparation of textile fibers from cellulosic pulps. Carbohydr Polym 173:253-258. https:// doi.org/10.1016/j.carbpol.2017.06.005

Alamri A, El-Newehy MH, Al-Deyab SS (2012) Biocidal polymers: synthesis and antimicrobial properties of benzaldehyde derivatives immobilized onto amine-terminated polyacrylonitrile. Chem Cent J 6:111. https://doi.org/10. 1186/1752-153X-6-111

Ali Elshafei A, El-Zanfaly HT (2011) Application of antimicrobials in the development of textiles. Asian J Appl Sci 4(6):585-595. https://doi.org/10.3923/ajaps.2011.585.595

Borkow G, Felix A, Gabbay J (2010) Copper-impregnated antimicrobial textiles; an innovative weapon to fight infection, In: MEDTEX: Medical and healthcare textiles, Woodhead Publishing Series in Textiles 75:14-22. https:// doi.org/10.1533/9780857090348.14

Camlibel NO, Arik B (2017) Sol-gel applications in textile finishing processes, in book Recent Applications in SolGel Synthesis, Ed Usha Chandra, IntechOpen 253-281. https://doi.org/10.5772/67686

Chen X, Fang F, Zhang X, Ding X, Wang Y, Chen L, Tian X (2016) Flame-retardant, electrically conductive and antimicrobial multifunctional coating on cotton fabric via layer-by-layer asssembly tecnioque. RCS Adv 6:27669-27676. https://doi.org/10.1039/C5RA26914H

Dumont M, Villet R, Guirand M, Montembault A, Delair T, Lack S, Barikosky M, Crepet A, Alcouffe P, Laurent F, David L (2018) Processing and antibacterial properties of chitosan-coated alginate fiber. Carbohyd Polym 190:31-42. https://doi.org/10.1016/j.carbpol.2017.11.088

Dufresne A (2013) Nanocellulose: A new ageless bionanomaterial. Mater Today 16:220-227. https://doi.org/10.1016/j. mattod.2013.06.004

El-Naggar ME, Shaarawy S, Hebeish AA (2018) Multifunctional properties of cotton fabrics coated with in situ synthesis of zinc oxide nanoparticles capped with date seed extract. Carbohyd Polym 181:307-316. https://doi.org/10. 1016/j.carbpol.2017.10.074

El-Shafei A, Shaarawy S, Motawe FH, Refaei R (2018) Herbal extract as an eco-friendly antimicrobial finishing of cotton fabric. Egypt J Chem 61(2):317-327

Ferrero F, Periolatto M, Ferrario S (2015) Sustainable antimicrobial finishing of cotton fabrics by chitosan UV-grafting: from laboratory experiments to semi industrial scale-up. J Clean Product 96:244-252. https://doi.org/10.1016/j. jclepro.2013.12.044

Ganesan P, Vardhini KJ (2015) Herbal treated microbial resistant fabrics for healthcare textiles. Indian $\mathrm{J}$ Nat Prod Resour 6(3):227-230 
Ghasemi S, Tajvidi M, Bousfield DW, Gardner DJ, Gramlich WM (2017) Dry-spun neat cellulose nanofibril filaments: influence of drying temperature and nanofibril structure on filament properties. Polymers 9(9):392. https://doi.org/10. 3390/polym9090392

Gorji M, Bagherzadeh R, Fashandi H (2017) Electrospun nanofibers in protective clothing in book Electrospun Nanofibers, Ed: Mehdi Afshari, Woodhead Publishing Series in Textiles, 571-598. https://doi.org/10.1016/B9780-08-100907-9.00021-0

Gokarnshan N, Nagarajan VB, Viswanath SR (2017) Developments in antimicrobial textiles-some insights on current research trends. Biomed J Sci \& Tech Res. https://doi.org/ 10.26717/BJSTR.2017.01.000160

Gün Gök Z, Günay K, Yiğitoğlu M, Vargel I (2020) Coating of modified poly(ethylene terephthalate) fibers with sericincapped silver nanoparticles for antimicrobial application. Polym Bull 77:1649-1665. https://doi.org/10.1007/ s00289-019-02820-0

Hasan R (2018) Production of antimicrobial textiles by using copper oxide nanoparticles. Int J Contemporary Res Rev 9(08):20195-20202

Harper BJ, Clendaniel A, Sinche F et al (2016) Impacts of chemical modification on the toxicity of diverse nanocellulose materials to developing zebrafish. Cellulose 23:1763-1775. https://doi.org/10.1007/s10570-016-09475

Hemraz UD, Boluk Y, Sunasee R (2013) Amine-decorated nanocrystalline cellulose surfaces: synthesis, characterization, and surface properties. Can J Chem 91(10):974-981. https://doi.org/10.1139/cjc-2013-0165

He L, Li S, Chung CTW, Gao C, Xin JH (2016) Constructing safe and durable antibacterial textile surfaces using a robust graft-to strategy via covalent bond formation. Sci Rep 6:36327. https://doi.org/10.1038/srep36327

Hooshmand S, Aitomäki Y, Norberg N, Mathew AP, Oksman K (2015) Dry-spun single-filament fibers comprising solely cellulose nanofibers from bioresidue. ACS Appl Mater Interfaces 7(23):13022-13028. https://doi.org/10.1021/ acsami.5b03091

Hui F, Debiemme-Chouvy C (2013) Antimicrobial N-halamine polymers and coatings: a review of their synthesis, characterization, and applications. Biomacromol 14(3):585-601. https://doi.org/10.1021/bm301980q

Ibrahim MM, Mezni A, El-Sheshtawy HS, Abu Zaid AA, Alsawat M, El-Shafi N, Ahmed SI, Shaltout AA, Amin MA, Kumeria T, Altalhi T (2019) Direct Z-scheme of $\mathrm{Cu} 2 \mathrm{O} / \mathrm{TiO} 2$ enhanced self-cleaning, antibacterial activity, and UV protection of cotton fiber under sunlight. Appl Surf Sci 479:953-962. https://doi.org/10.1016/j.apsusc.2019. 02.169

Jahani B, Brooks A, Jahani F (2018) Development of antibacterial surfaces via thermal spray coating techniques. Biomed Sci Instrum 54(1):116-122

Jin LQ, Li WG, Xu QH, Sun QC (2015) Amino-functionalized nanocrystalline cellulose as an adsorbent for anionic dyes. Cellulose 22:2443-2456. https://doi.org/10.1007/s10570015-0649-4

Kang CK, Kim SS, Kim S, Lee J, Lee J (2016) Antibacterial cotton fibers treated with silver nanoparticles and quaternary ammonium salts. Carbohydr Polym 151:1012-1018. https://doi.org/10.1016/j.carbpol.2016. 06.043

Kampeerapappun P (2012) Preparation characterization and antimicrobial activity of electrospun nanofibers from cotton waste fibers. Chiang Mai J Sci 39:712-722

Kaisersberger-Vincek M, Štrancar J, Kokol V (2017) Antibacterial activity of chemically versus enzymatic functionalized wool with $\varepsilon$-poly-L-lysine. Text Res J 87(13):1604-1619

Khan MQ, Kharaghani D, Nishat N, Shahzad A, Hussain T, Khatri Z, Zhu C, Kim IS (2019) Preparation and characterizations of multifunctional PVA/ZnO nanofibers composite membranes for surgical gown application. J Mat Res Technol 8(1):1328-1334. https://doi.org/10.1016/j.jmrt. 2018.08.013

Kim UJ, Kuga S, Wada M (2004) Solubilizaton of dialdehyde cellulose by hot water. Carbohydr Polym 56(1):7-10. https://doi.org/10.1016/j.carbpol.2003.10.013

Kim YH, Sun G (2001) Durable antimicrobial finishing of nylon fabrics with acid dyes and a quaternary ammonium salt. Text Res J 71(4):318-323. https://doi.org/10.1177/ 004051750107100407

Kwak HW, Kim JE, Lee KH (2019) Green fabrication of antibacterial gelatin fiber for biomedical application. React Funct Polym 136:86-94

Lim SH, Hudson SM (2003) Review of chitosan and its derivatives as antimicrobial agents and their uses as textile chemicals. J Macromol Sci Part C 43(2):223-269. https:// doi.org/10.1081/MC-120020161

Liu S, Sun G (2006) Durable and regenerable biocidal polymers: Acyclic N-halamine cotton cellulose. Ind Eng Chem Res 45(19):6477-6482. https://doi.org/10.1021/ie060253m

Liu X, Lin T, Peng B, Xungai W (2012) Antibacterial activity of capsaicin-coated wool fabric. Text Res J 82(6):584-590. https://doi.org/10.1177/0040517511426608

Liimatainen H, Visanko M, Sirviö JA, Hormi OEO, Niinimaki J (2012) Enhancement of the nanofibrillation of wood cellulose through sequential periodate-chlorite oxidation. Biomacromol 13(5):1592-1597. https://doi.org/10.1021/ bm300319m

Mahltig B, Textor T (2010) Silver containing sol gel coating on polyamide fabrics as antimicrobial finish description of a technical application proces for wash permanent antimicrobial effect. Fibers Polym 11(8):1152-1158. https://doi. org/10.1007/s12221-010-1152-z

Marković D, Korica M, Kostić M, Radovanović Ž, Šaponjić Z, Mitrić M, Radetić M (2018) In situ synthesis of $\mathrm{Cu} / \mathrm{Cu} 2 \mathrm{O}$ nanoparticles on the TEMPO oxidized cotton fabrics. Cellulose 25(1):829-841. https://doi.org/10.1007/s10570017-1566-5

Milošević M, Šaponjić Z, Nunney TD, C, Radoičić M, Mitrić M, Radetić T, Radetić M, (2017) In situ photoreduction of $\mathrm{Ag}^{+}$-ions on the surface of titania nanotubes deposited on cotton and cotton/PET fabrics. Cellulose 24:1597-1610

Mohy Eldin MS, Soliman EA, Hashem AI, Tamer TM (2012) Antimicrobial activity of novel aminated chitosan derivatives for biomedical applications. Inc Adv Polym Techn 31:414-428. https://doi.org/10.1002/adv.20264

Muňoz-Bonila A, Cerrado ML, Fernández-Garcia M (2014) Introduction to Antimicrobial Polymeric Materials. In: 
Muñoz-Bonilla A, Cerrada M, Fernández-García M (eds) Polymeric materials with antimicrobial activity: from synthesis to applications. The Royal Society of Chemistry, Cambridge, UK, pp 1-21. https://doi.org/10.1039/ 9781782624998-00001

Nayak R, Padhye R (2015) Antimicrobial finishes for textiles. In: Roshan $\mathrm{P}$ (ed) Functional finishes for textiles: improving comfort, performance and protection. Woodhead Publishing Series in Textil, pp 1-14. https://doi.org/ 10.1533/9780857098450.1

Pajoumshariati S, Yavari SK, Shokrgozar MA (2016) Physical and biological modification of polycaprolactone electrospun nanofiber by panax ginseng extract for bone tissue engineering application. Ann Biomed Eng 44(5):1808-1820. https://doi.org/10.1007/s10439-0151478-1

Periolatto M, Ferrero F, Vineis C (2012) Antimicrobial chitosan finish of cotton and silk fabrics by UV-curing with 2-hydroxy-2-methylphenylpropane-1-one. Carbohyd Polym 88(1):201-205. https://doi.org/10.1016/j.carbpol.2011.11. 093

Peets P, Kaupmees K, Vahur S, Leito I (2019) Reflectance FTIR spectroscopy as a viable option for textile fiber identification. Herit Sci 7:93. https://doi.org/10.1186/s40494019-0337-z

Poli R, Colleoni C, Calvimontes A, Polášková H, Dutschk V, Rosace G (2015) Innovative sol-gel route in neutral hydroalcoholic condition to obtain antibacterial cotton finishing by zinc precursor. J Sol-Gel Sci Technol 74:151-160. https://doi.org/10.1007/s10971-014-3589-9

Prado-Prone G, Silva-Bermudez P, Almaguer-Flores A, GarcíaMacedo JA, Velasquillo C (2018) Enhanced antibacterial nanocomposite mats by coaxial electrospinning of polycaprolactone fibers loaded with $\mathrm{Zn}$-based nanoparticles. Nanomedicine 14(5):1695-1706. https://doi.org/10.1016/j. nano.2018.04.005

Rajendra R, Balakumar C, Ahammed HAM, Jayakumar S, Vaideki K, Rajesh E (2010) Use of zinc oxide nano particles for production of antimicrobial textiles. Int J Eng Sci Tech 2(1):202-208. https://doi.org/10.4314/ijest.v2i1. 59113

Ren X, Jiang Z, Liu Y, Li L, Fan X (2016) N-halamines as antimicrobial textile finishes. In (Ed Gang Sun) Antimicrobial Textiles. Woodhead Publishing, pp 125-140. https://doi.org/10.1016/B978-0-08-100576-7.00008-0

Rezaie AB, Montazer M, Rad MM (2017) A cleaner route for nanocolouration of wool fabric via green assembling of cupric oxide nanoparticles along with antibacterial and UV protection properties. J Clean Prod 166:221-231. https:// doi.org/10.1016/j.jclepro.2017.08.046

Rieger KA, Schiffman JD (2014) Electrospinning an essential oil: Cinnamaldehyde enhances the antimicrobial efficacy of chitosan/poly(ethylene oxide) nanofibers. Carbohyd Polym 113:561-568. https://doi.org/10.1016/j.carbpol. 2014.06.075

Sataev MS, Koshkarbaeva ST, Tleuova AB, Perni S, Aidarova SB, Prokopovich P (2014) Novel process for coating textile materials with silver to prepare antimicrobial fabrics. Colloid Surf A Physicochem Eng 442:146-151. https://doi. org/10.1016/j.colsurfa.2013.02.018
Song MS, Hou JB, Lu YH, Lin J, Cheng DH (2013) Performance of foam and application in foam finishing of textile. Adv Mat Res 821:661-664

Sridhar R, Lakshminarayanan R, Madhaiyan K, Amutha Barathi V, Lim KH, Ramakrishna S (2015) Electrosprayed nanoparticles and electrospun nanofibers based on natural materials: applications in tissue regeneration, drug delivery and pharmaceuticals. Chem Soc Rev 44(3):790-814. https://doi.org/10.1039/c4cs00226a

Suganya S, Senthil Ram T, Lakshmi BS, Giridev VR (2011) Herbal drug incorporated antibacterial nanofibrous mat fabricated by electrospinning: an excellent matrix for wound dressings. J Appl Polym Sci 121:2893-2899. https://doi.org/10.1002/app.33915

Sun L, Xiao G, Qian X, An X (2019) Alkyne functionalized cellulose fibers: a versatile "clickable" platform for antibacterial materials. Carbohyd Polym 207:68-78. https://doi.org/10.1016/j.carbpol.2018.11.068

Teli MD, Mathur P, Chavan P (2017) Development of multifunctional non-woven fabrics by electro spinning for medical protection. Int Res J Eng Technol 4(1):63-68

Upadhyay A, Upadhyaya I, Kollanoor-Johny A, Venkitanarayanan K (2014) Combating pathogenic microorganisms using plant-derived antimicrobials: a minireview of the mechanistic basis. Biomed Res Int 2014:761741. https://doi.org/10.1155/2014/761741

Varaprasad K, Raghavendra GM, Jayaramudu T, Seo J (2016) Nano zinc oxide-sodium alginate antibacterial cellulose fibres. Carbohyd Polym 135:349-355. https://doi.org/10. 1016/j.carbpol.2015.08.078

Velmurugan P, Lee SM, Cho M, Park JH, Seo SK, Myung H, Bang KS, Oh BT (2014) Antibacterial activity of silver nanoparticle-coated fabric and leather against odor and skin infection causing bacteria. Appl Microbiol Biotechnol 98(19):8179-8189. https://doi.org/10.1007/s00253-0145945-7

Ugur S, Sarışık M, Türkoğlu G, Erkan G, Erden E (2016) Layer by layer assembly of antibacterial inclusion complexes. Int J Clothing Sci Tech 28(3):368-377. https://doi.org/10. 1108/IJCST-03-2016-0032

Vastrad JV, Byadgi SA (2018) Eco-friendly antimicrobial finishing of cotton fabric using plant extracts. Int J Curr Microbiol App Sci 7(2):284-292

Vivod V, Neral B, Mihelič A, Kokol V (2019) Highly efficient film-like nanocellulosebased adsorbents for the removal of loose reactive dye during textile laundering. Text Res J 89(6):975-988

Xiao H, Qian L (2014) Water-soluble antimicrobial polymers for functional cellulose fibres and hygiene paper products. In (ed: Muñoz-Bonilla A, Cerrada M, Fernández-García M): Polymeric Materials with Antimicrobial Activity: From Synthesis to Applications. The Royal Society of Chemistry, Cambridge, UK, pp. 75-96. https://doi.org/10. 1039/9781782624998-00075

Xu Q, Ke X, Shen L, Ge N, Zhang Y, Fu F, Liu X (2018) Surface modification by carboxymethy chitosan via pad-dry-cure method for binding Ag NPs onto cotton fabric. Int J Biol Macromol 111:796-803. https://doi.org/10.1016/j. ijbiomac.2018.01.091

Zhou H, Zhou J, Wang T, Zeng J, Liu G (2018) In-situ preparation of silver salts/collagen fiber hybrid composites and 
their photocatalytic and antibacterial activities. J Hazard Mater 359:274-280. https://doi.org/10.1016/j.jhazmat. 2018.07.043
Publisher's Note Springer Nature remains neutral with regard to jurisdictional claims in published maps and institutional affiliations. 